\title{
$\mathrm{LC}-\mathrm{MS} / \mathrm{MS}$ 와 GC-MS/MS를 이용한 사과와 쌀 시료에서 320 종 농약의 다성분 분석
}

김종환 · 김영진 · 권영상 · 서종수*

안전성평가연구소 환경독성연구센터

\section{Development of Multi-residue Analysis of 320 Pesticides in Apple and Rice Using LC-MS/MS and GC-MS/MS}

\author{
Jong-Hwan Kim, Yeong-Jin Kim, Young-Sang Kwon and Jong-Su Seo* \\ Environmental Toxicology Research Center, Korea Institute of Toxicology, Jinju 52834, Korea
}

(Received on March 25, 2016. Revised on May 27, 2016. Accepted on June 17, 2016)

\begin{abstract}
A new analytical method has been developed to determine 320 pesticides in apple and rice. The extraction of pesticides was carried out based on QuEChERS sample extraction, and determination was performed using LC-MS/MS and GC-MS/MS. 320 pesticides were selected for experiments. 251 and 110 pesticides among them were analysed by LC-MS/MS and GC-MS/MS, respectively. 41 pesticides of them were analyzed by both GC-MS/MS and LC-MS/MS. Among pesticides analysed by LC, 242 pesticides $(96 \%$ of total number) in apple and 237 pesticides (94\% of total number) in rice showed recoveries in the range of $70 \sim 120 \%$ with RSD $\leq 20 \%$. In case of pesticides analyzed by GC-MS/MS, 103 pesticides (94\% of total number) in apple and 83 pesticides (76\% of total number) in rice were successfully validated. These results indicated that LC-MS/MS and GC-MS/MS analysis with the QuEChERS sample preparation can be partly applied to multi-residue pesticides in agricultural products.
\end{abstract}

Key words GC-MS/MS, LC-MS/MS, Multiresidue analysis, Pesticide, QuEChERS

\section{서 론}

농약은 현대 농업에 있어 작부체계 및 재배방법 개선, 품 질과 저장성의 향상 및 노동력 절감, 생산량 증대 등을 위한 중요하고도 필수적인 농업자재이다(Fenik 등, 2011; Lee 등, 2013). 그러나 농작물에 살포된 농약은 사용목적을 달성한 후 환경에서 분해되어 잔류하지 않는 것이 가장 이상적이지 만 농약은 대부분 유기합성물질로서 자체의 물리화학적 특 성에 따라 농작물 및 토양 등 재배환경 중에 잔류하게 된다 (Do 등, 2010; Lee 등, 2008). 잔류농약은 농산물을 섭취하 는 단계에서 인체에 흡수, 축적되어 안전성 문제를 발생시킬 가능성이 있으므로 효율적인 농산물 안전관리를 위해서는 잔류농약에 대한 지속적인 연구와 모니터링이 필요하다.

*Corresponding author

E-mail: jsseo@kitox.re.kr
현재 세계 각국에서는 농산물 안전성 확보를 위하여 자국 에서 생산된 농산물 뿐만 아니라 수입산 농산물에 대해서도 유해물질 규제와 검역기준을 대폭 강화하고 있으며, 농산물 을 통해 섭취될 수 있는 잔류농약에 대한 안전성을 확보하 기 위하여 국가마다 농산물에 대한 농약안전사용기준과 농 약의 최대잔류허용기준(Maximum Residue Limits, MRLs) 을 설정하여 관리하고 있다(Bhanti 등, 2007). 또한, 농식품 의 안전성에 대한 소비자의 높은 관심에 따라 농식품 내의 유해물질을 신속 정확하게 분석하는 기술이 중요시 되고 있 다. 그 중에서도 대표적인 유해 물질인 잔류농약 분석은 다 양한 매트릭스 내에 존재하는 극미량의 성분을 분석하기 위 해 농약 이외의 복잡한 불순물을 선택적으로 제거해야하는 정제방법이 복잡할 뿐만 아니라 분석결과의 공적, 법적 사 용을 위하여 높은 신뢰성이 요구되기 때문에 많은 시간과 비용, 분석자의 숙련된 기술이 요구된다(Lee 등, 2012).

최근 농식품 중의 잔류농약 분석을 위해 전처리방법을 간 
소화 시키면서 고감도 질량분석기를 이용하여 신속하게 분 석하는 방법이 필수적이기에 대부분 다종다성분 분석법이 적용되고 있다(Guana 등, 2010; Ju 등, 2011; Kwon 등, 2011; Zhang 등; 2011). QuEChERS (Quick, Easy, Cheap, Effective, Rugged and Safe) 전처리법은 미농무성 농업연구 소(Agricultural Research Service)에서 개발되어 AOAC 및 European Committee에서 농약다성분 분석법으로 인정받았 으며(Anastassiades 등, 2003; Lehotay 등, 2010), 기존 농약 잔류분석법과 달리 분석방법이 간단하고 개발이 쉬운 장점 을 가지고 있어 다양한 시료를 대상으로 농약의 다성분분석 뿐만 아니라 농약의 대사물질을 동시 분석하는데도 적용이 가능하다(Cajka 등, 2008; Ju 등, 2011; Koesukwiwat 등, 2010; Seo 등, 2013). 또한, 최근 국외 잔류 농약 분석에 관 한 연구는 $\mathrm{GC} / \mathrm{MS} / \mathrm{MS}$ 와 $\mathrm{LC} / \mathrm{MS} / \mathrm{MS}$ 를 동시에 적용한 농약 다성분 분석연구가 수행되어지고 있다(Chamkasem 등, 2013; Lehotay 등, 2005; Pang 등, 2006).

따라서 본 연구에서는 최근 사용 빈도가 높은 국내 등록 농약에 대한 잔류분석법을 확립하기 위하여 $\mathrm{LC}-\mathrm{MS} / \mathrm{MS}$ 와 $\mathrm{GC}-\mathrm{MS} / \mathrm{MS}$ 를 이용하여 다종농약 다성분 동시분석법 적용 시험을 수행하였다.

\section{재료 및 방법}

\section{농약표준용액 및 시약}

분석에 사용한 표준품은 HPC Standards $\mathrm{GmbH}$ (Cunnersdorf, Germany), AccuStandard (New Haven, CT, USA), LGC Standard (Teddington Middlesex, UK), Wako Pure Chemical (Osaka, Japan)로부터 구입하였으며 각각의 농약 표준품은 acetone, acetonitrile으로 $1,000 \mathrm{mg} / \mathrm{L}$ 의 용액을 $\mathrm{LC}-\mathrm{MS} / \mathrm{MS}$ 및 $\mathrm{GC}-\mathrm{MS} / \mathrm{MS}$ 분석용 혼합표준용액 $(5 \mathrm{mg} / \mathrm{L})$ 조제하여 $4^{\circ} \mathrm{C}$ 냉장보관 하여 사용하였다.

분석에 사용된 용매인 formic acid $(98 \%)$ 는 Junsei Chemical (Tokyo, Japan), ammonium formate (99.995\%)는 SigmaAldrich (Steinheim, Germany) 제품을 구입 하였다. 시료 추 출 및 정제를 위해 사용한 acetonitrile, acetone, methanol은 Burdick\&Jackson (Muskegon, MI, USA)로부터 구입하여 사용하였고, QuEChERS법 추출을 위해 QuEChERS Extract Kit (magnesium sulfate; 98.5 101.5\%, sodium chloride; $\geq 99.5 \%$, sodium citrate; $99.9 \%$, disodium citrate sesquihydrate; $99 \%$ )와 정제를 위해 사용된 QuEChERS dispersive SPE $2 \mathrm{~mL}$ (primary secondary amine (PSA), octadecysilane end-capped, magnesium sulfate; 98.5 101.5\%)은 Agilent (Boblingen, Germany)로부터 구입하여 사용하였다.

\section{전처리방법}

시험에 사용된 사과와 쌀은 친환경인증을 받은 무농약 시

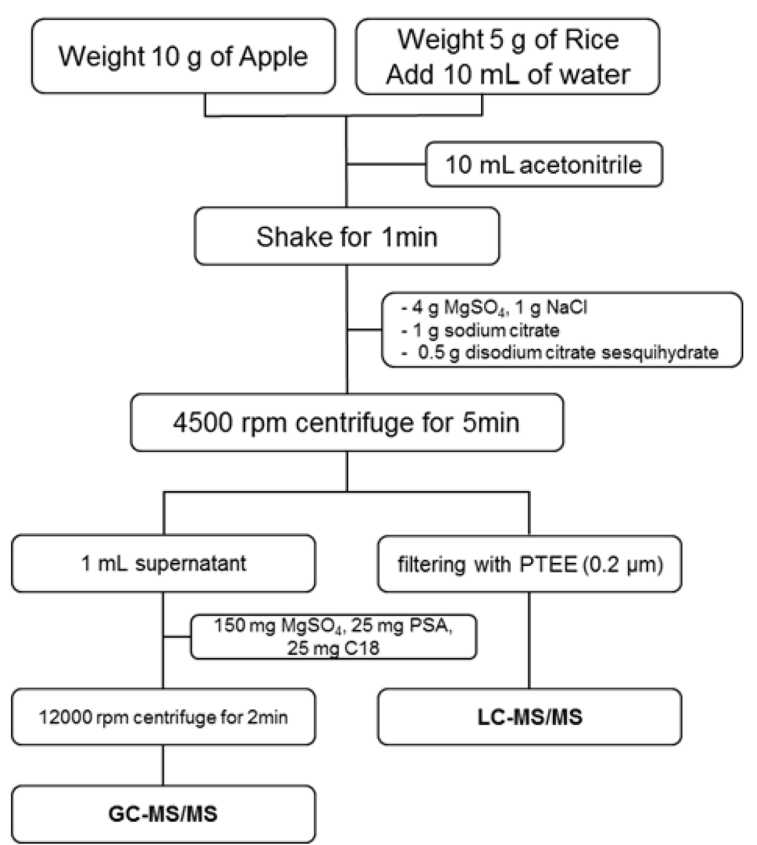

Fig. 1. Flow chart diagram of QuEChERS preparation for pesticides analysis.

료로 분쇄기를 이용하여 균질화한 후 회수율 시험 및 blank 시료로 사용하였고 쌀시료의 경우 분쇄한 시료 $5 \mathrm{~g}$ 을 칭량 하여 증류수 $10 \mathrm{~mL}$ 넣고 1시간 습윤화 시켜 분석시료로 사 용하였으며, 칭량된 각 시료에 acetonitrile $10 \mathrm{~mL}$ 을 넣고 1 분간 진탕하였다. 사과와 쌀 추출액에 $4 \mathrm{~g}$ 의 anhydrous magnesium sulfate, $1 \mathrm{~g}$ 의 sodium chloride, $1 \mathrm{~g}$ 의 sodium citrate, $0.5 \mathrm{~g}$ 의 disodium citrate sesquihydrate 를 첨가 후 ceramic homogenizers를 이용하여 1 분간 강하게 진탕 하였 으며, 진탕한 시료는 원심분리기를 이용하여 $4,500 \mathrm{rpm}$ 에서 5 분간 원심분리를 하였다. Acetonitrile층과 water층을 분리 후, $\mathrm{GC}-\mathrm{MS} / \mathrm{MS}$ 분석을 위해서는 시료의 상징액 $1 \mathrm{~mL}$ 을 $25 \mathrm{mg}$ PSA, $150 \mathrm{mg}$ magnesium sulfate $\left(\mathrm{MgSO}_{4}\right), 25 \mathrm{mg}$ C18EC (octadecysilane, end-capped)가 충진되어 있는 dispersive SPE tube에 넣고 1분간 진탕 후 $12,000 \mathrm{rpm}$ 으로 2분간 원심분리하여 시액으로 사용하였고, LC-MS/MS 분석을 위 해서는 상징액을 $0.2 \mu \mathrm{m}$ syringe filter (Whatman, PTFE)로 여과하여 시액으로 사용하였다(Fig. 1).

농약성분의 정량분석을 위한 검량선은 각각의 표준품을 acetonitrile에 녹여 $1,000 \mathrm{mg} / \mathrm{L}$ 의 stock solution을 조제한 후 무처리 시료 추출액과 혼합하여 $10,25,100,150,200$ 및 $250 \mu \mathrm{g} / \mathrm{L}$ 농도로 matrix matched calibration을 작성하였 다. 각 농약성분에 대한 회수율 시험은 50 및 $200 \mu \mathrm{g} / \mathrm{kg}$ 수 준에서 결과를 확인하였다.

\section{기기분석 조건}

LC-MS/MS는 Agilent Technologies사의 6460 Triple Quad 
Table 1. Analytical conditions of LC-MS/MS

\begin{tabular}{|c|c|c|c|c|}
\hline Instrument & \multicolumn{4}{|c|}{ : Agilent 6460 Triple Quad LC/MS with Agilent 1260 series HPLC } \\
\hline Column & \multicolumn{4}{|c|}{ : Agilent Poroshell 120 EC-C18, $2.1 \times 100$ mm, I.d., $2.7 \mu \mathrm{m}$} \\
\hline Mobile phase A & \multicolumn{4}{|c|}{ : $5 \mathrm{mM}$ ammonium formate $\& 0.1 \%$ formic acid in water } \\
\hline Mobile phase B & \multicolumn{4}{|c|}{ : $5 \mathrm{mM}$ ammonium formate \& $0.1 \%$ formic acid in methanol } \\
\hline & Time (min) & $\mathrm{A}(\%)$ & $\mathrm{B}(\%)$ & Flow (mL/min) \\
\hline & Initial & 85 & 15 & 0.3 \\
\hline & 1 & 85 & 15 & 0.3 \\
\hline & 1.5 & 40 & 60 & 0.3 \\
\hline \multirow[t]{5}{*}{ Gradient program } & 10 & 10 & 90 & 0.3 \\
\hline & 15 & 10 & 90 & 0.3 \\
\hline & 20 & 2 & 98 & 0.3 \\
\hline & 20.1 & 85 & 15 & 0.3 \\
\hline & 25 & 85 & 15 & 0.3 \\
\hline Injection volume & \multicolumn{4}{|l|}{$: 1 \mu \mathrm{L}$} \\
\hline Column temperature & \multicolumn{4}{|l|}{$: 40^{\circ} \mathrm{C}$} \\
\hline Sample Tray Temp. & \multicolumn{4}{|l|}{$: 10^{\circ} \mathrm{C}$} \\
\hline Ionization mode & \multicolumn{4}{|l|}{ : ESI positive } \\
\hline Gas temperature & \multicolumn{4}{|l|}{$: 325^{\circ} \mathrm{C}$} \\
\hline Gas Flow & \multicolumn{4}{|l|}{$: 6 \mathrm{~mL} / \mathrm{min}$} \\
\hline Nebulizer gas pressure & \multicolumn{4}{|l|}{ : 35 psi } \\
\hline Ionspray voltage & \multicolumn{4}{|l|}{$:+4000 \mathrm{~V}$} \\
\hline Scan type & \multicolumn{4}{|c|}{ : Dynamic MRM mode } \\
\hline
\end{tabular}

Table 2. Analytical conditions of GC-MS/MS

\begin{tabular}{|c|c|c|c|c|}
\hline Instrument & \multicolumn{4}{|l|}{ : Bruker SCION TQ } \\
\hline Column & \multicolumn{4}{|c|}{ : BR-5ms, $30 \mathrm{~m} \times 0.25 \mathrm{~mm}$ i.d., $0.25 \mu \mathrm{m}$} \\
\hline Flow rate & \multicolumn{4}{|c|}{ : Helium $(99.999 \%)$ at $1.5 \mathrm{~mL} / \mathrm{min}$} \\
\hline Injection vol., mode & \multicolumn{4}{|c|}{$: 1 \mu \mathrm{L}$, split ratio $50: 1,260^{\circ} \mathrm{C}$} \\
\hline \multirow{4}{*}{ Column oven } & Temperature $\left({ }^{\circ} \mathrm{C}\right)$ & Rate $\left({ }^{\circ} \mathrm{C} / \mathrm{min}\right)$ & Hold (min) & Total (min) \\
\hline & 90 & & 3 & 3 \\
\hline & 120 & 20 & 0 & 4.5 \\
\hline & 300 & 8 & 3 & 30 \\
\hline Source temperature & \multicolumn{4}{|l|}{$: 200^{\circ} \mathrm{C}$} \\
\hline Transfer line & \multicolumn{4}{|l|}{$: 280^{\circ} \mathrm{C}$} \\
\hline Manifold & \multicolumn{4}{|l|}{$: 40^{\circ} \mathrm{C}$} \\
\hline Ionization & \multicolumn{4}{|c|}{ : Electron ionization $(\mathrm{EI}), 70 \mathrm{eV}$} \\
\hline Scan mode & \multicolumn{4}{|c|}{ : MRM (Multiple Reaction Monitoring) mode } \\
\hline
\end{tabular}

$\mathrm{LC} / \mathrm{MS}$ 기기를 사용하였고, 데이터 처리는 MassHunter Quantitative Analysis 소프트웨어를 사용하였다. GC-MS/ $\mathrm{MS}$ 는 Bruker사의 SCION TQ 기기를 사용하였고, 데이터 처리는 MS Work Station 8을 사용하였다. 분석 조건은 Table 1과 2에 나타내었다. LC-MS/MS 분석대상 농약 251 종과 $\mathrm{GC}-\mathrm{MS} / \mathrm{MS}$ 분석대상 농약 110 종에 대한 $\mathrm{MRM}$ 조건 은 각각 Table 3 과 4에 나타내었다.

\section{회수율, 검출한계 및 정량한계의 측정}

본 연구에서 잔류농약 분석법의 효율과 신뢰성을 검정 하기 위하여 회수율 시험을 진행하였다. 회수율 시험은 무처리 사과와 쌀 시료에 첨가농도가 $50 \mu \mathrm{g} / \mathrm{kg}, 200 \mu \mathrm{g} /$ $\mathrm{kg}$ 이 되도록 표준용액을 첨가한 다음 상기 전처리방법에 따라 회수율 시험을 3반복 수행하였다. 검출한계(limits of detection, LOD)와 정량한계(limits of quantification, $\mathrm{LOQ}$ )는 각 농도별 표준용액을 시료에 spiking하여 분석 
Table 3. Parameters for 251 pesticide residue analysis by LC-MS/MS

\begin{tabular}{|c|c|c|c|c|c|c|c|c|}
\hline No. & Pesticides & $\begin{array}{l}\text { Retention } \\
\text { time (min) }\end{array}$ & Parent ion & $\begin{array}{l}\text { Quantitative ion } \\
(\mathrm{m} / \mathrm{z})\end{array}$ & $\begin{array}{l}\text { Collision } \\
\text { energy (V) }\end{array}$ & $\begin{array}{l}\text { Qualitative ion } \\
(\mathrm{m} / \mathrm{z})\end{array}$ & $\begin{array}{l}\text { Collision } \\
\text { energy (V) }\end{array}$ & $\begin{array}{l}\text { Fragmentor } \\
\text { Voltage (V) }\end{array}$ \\
\hline 1 & Abamectin B1 & 12.3 & 890.5 & 145.0 & 30 & 113.2 & 50 & 140 \\
\hline 2 & Acephate & 1.0 & 184.0 & 143.0 & 5 & 95.0 & 20 & 90 \\
\hline 3 & Acetamiprid & 4.1 & 223.1 & 126.0 & 20 & 56.2 & 20 & 100 \\
\hline 4 & Acibenzolar-S-methyl & 6.2 & 211.0 & 136.1 & 28 & 91.2 & 16 & 120 \\
\hline 5 & Alachlor & 7.2 & 270.1 & 238.1 & 10 & 162.1 & 15 & 80 \\
\hline 6 & Aldicarb & 4.5 & 116.1 & 89.0 & 5 & 70.1 & 5 & 80 \\
\hline 7 & Ametoctradin & 8.7 & 276.1 & 176.1 & 30 & 149.0 & 30 & 170 \\
\hline 8 & Amisulbrom & 9.2 & 466.0 & 227.0 & 18 & 107.8 & 18 & 100 \\
\hline 9 & Amitraz & 11.2 & 294.0 & 163.0 & 9 & 121.9 & 30 & 90 \\
\hline 10 & Azimsulfuron & 5.4 & 424.9 & 181.9 & 10 & 155.9 & 34 & 110 \\
\hline 11 & Azinphos-methyl & 5.8 & 318.0 & 132.1 & 8 & 77.0 & 40 & 80 \\
\hline 12 & Azoxystrobon & 6.0 & 404.2 & 372.2 & 11 & 344.2 & 20 & 100 \\
\hline 13 & Bendiocarb & 4.8 & 224.1 & 167.1 & 5 & 109.0 & 10 & 80 \\
\hline 14 & Benfuracarb & 9.42 & 411.0 & 251.9 & 8 & 194.9 & 20 & 100 \\
\hline 15 & Benfuresat & 14.9 & 391.2 & 149.1 & 16 & 65.2 & 84 & 104 \\
\hline 16 & Bensulfuron-methyl & 5.8 & 410.9 & 148.9 & 15 & 181.9 & 20 & 120 \\
\hline 17 & Benthiavalicarb-Isopropyl & 6.6 & 382.2 & 180.1 & 29 & 116.1 & 20 & 120 \\
\hline 18 & Benzobicyclon & 6.5 & 446.9 & 256.9 & 24 & 228.9 & 40 & 160 \\
\hline 19 & Benzoximate & 8.4 & 364.1 & 199.0 & 10 & 105.1 & 31 & 100 \\
\hline 20 & Bifenazate & 6.8 & 301.2 & 198.0 & 4 & 170.0 & 16 & 75 \\
\hline 21 & Bitertanol & 8.4 & 338.2 & 70.1 & 10 & 99.1 & 10 & 100 \\
\hline 22 & Boscalid & 6.3 & 343.1 & 307.1 & 20 & 140.0 & 20 & 100 \\
\hline 23 & Bromacil & 4.8 & 261.0 & 204.9 & 4 & 131.9 & 44 & 80 \\
\hline 24 & Buprofezin & 9.7 & 306.2 & 116.1 & 14 & 201.1 & 14 & 100 \\
\hline 25 & Cadusafos & 8.7 & 271.1 & 159.0 & 10 & 97.0 & 49 & 90 \\
\hline 26 & Cafenstrol & 6.7 & 351.2 & 100.1 & 3 & 72.1 & 28 & 50 \\
\hline 27 & Carbarl (NAC) & 5.0 & 202.1 & 145.0 & 4 & 127.0 & 20 & 60 \\
\hline 28 & Carbendazim & 3.7 & 192.1 & 160.1 & 20 & 132.1 & 30 & 110 \\
\hline 29 & Carbofuran & 4.8 & 222.2 & 165.0 & 14 & 123.0 & 16 & 100 \\
\hline 30 & Carboxin & 5.0 & 236.1 & 142.9 & 8 & 87.0 & 20 & 85 \\
\hline 31 & Carfentrazone-ethyl & 7.7 & 412.1 & 345.9 & 20 & 365.9 & 12 & 150 \\
\hline 32 & Carpropamid & 7.9 & 334.1 & 139.0 & 20 & 103.0 & 40 & 100 \\
\hline 33 & Chlorantraniliprole & 5.8 & 484.0 & 285.9 & 13 & 452.8 & 15 & 100 \\
\hline 34 & Chlorfluazron & 11.3 & 540.0 & 382.9 & 20 & 347.0 & 50 & 120 \\
\hline 35 & Chlorpyrifos & 10.2 & 350.0 & 97.1 & 25 & 197.9 & 25 & 60 \\
\hline 36 & Chlorsulfuron & 4.9 & 358.0 & 141.0 & 16 & 167.0 & 12 & 105 \\
\hline 37 & Chromafenozide & 6.9 & 395.2 & 175.1 & 20 & 147.0 & 55 & 100 \\
\hline 38 & Clethodim & 6.6 & 360.1 & 164.1 & 16 & 136.1 & 24 & 97 \\
\hline 39 & Clofentezine & 8.3 & 303.0 & 138.0 & 20 & 102.0 & 55 & 100 \\
\hline 40 & Clomazone & 5.9 & 240.1 & 124.9 & 16 & 89.0 & 52 & 105 \\
\hline 41 & Clothianidin & 3.9 & 250.0 & 132.0 & 20 & 169.0 & 20 & 100 \\
\hline 42 & Cyazofamid & 7.2 & 325.1 & 108.0 & 11 & 261.2 & 11 & 100 \\
\hline 43 & Cyclosulfamuron & 6.8 & 422.1 & 260.9 & 12 & 217.9 & 24 & 110 \\
\hline 44 & Cyflufenamid & 8.4 & 413.2 & 203.1 & 38 & 241.2 & 13 & 120 \\
\hline 45 & Cyhalofop-butyl & 9.0 & 358.2 & 256.0 & 28 & 120.0 & 8 & 90 \\
\hline
\end{tabular}


Table 3. Continued

\begin{tabular}{|c|c|c|c|c|c|c|c|c|}
\hline No. & Pesticides & $\begin{array}{l}\text { Retention } \\
\text { time (min) }\end{array}$ & Parent ion & $\begin{array}{l}\text { Quantitative ion } \\
(\mathrm{m} / \mathrm{z})\end{array}$ & $\begin{array}{l}\text { Collision } \\
\text { energy (V) }\end{array}$ & $\begin{array}{l}\text { Qualitative ion } \\
\qquad(\mathrm{m} / \mathrm{z})\end{array}$ & $\begin{array}{l}\text { Collision } \\
\text { energy (V) }\end{array}$ & $\begin{array}{l}\text { Fragmentor } \\
\text { Voltage (V) }\end{array}$ \\
\hline 46 & Cymoxanil & 4.2 & 199.1 & 128.0 & 4 & 111.0 & 12 & 61 \\
\hline 47 & Cyproconazole & 6.6 & 292.1 & 70.1 & 16 & 125.0 & 30 & 100 \\
\hline 48 & Cyprodinil & 7.4 & 226.2 & 77.1 & 50 & 93.1 & 50 & 120 \\
\hline 49 & Cyromazine & 0.9 & 167.1 & 85.0 & 16 & 125.1 & 16 & 100 \\
\hline 50 & DDVP (Dichlovos) & 4.8 & 221.0 & 109.0 & 19 & 126.9 & 19 & 120 \\
\hline 51 & Dinotefuran & 2.3 & 203.1 & 129.2 & 4 & 114.2 & 8 & 81 \\
\hline 52 & Diafenthiuron & 11.0 & 385.2 & 329.1 & 16 & 278.1 & 32 & 140 \\
\hline 53 & Diazinon & 8.0 & 305.1 & 169.1 & 20 & 153.1 & 20 & 160 \\
\hline 54 & Dichlofluanid & 6.8 & 350.0 & 224.1 & 10 & 123.1 & 35 & 100 \\
\hline 55 & Diethofencarb & 6.1 & 268.2 & 180.1 & 13 & 226.1 & 13 & 80 \\
\hline 56 & Difenoconazole & 8.8 & 406.1 & 251.0 & 20 & 337.1 & 19 & 100 \\
\hline 57 & Diflubenzuron & 7.4 & 311.1 & 158.2 & 8 & 141.1 & 36 & 90 \\
\hline 58 & Dimepiperate & 8.9 & 264.1 & 119.0 & 10 & 146.0 & 5 & 100 \\
\hline 59 & Dimethametryn & 7.2 & 256.0 & 186.0 & 18 & 91.0 & 26 & 130 \\
\hline 60 & Dimethenamid & 6.3 & 276.1 & 244.1 & 16 & 168.2 & 16 & 80 \\
\hline 61 & Dimethoate & 4.1 & 230.0 & 199.0 & 5 & 171.0 & 10 & 80 \\
\hline \multirow[t]{2}{*}{62} & Dimethomorph (1) & 6.2 & 388.2 & 301.1 & 20 & 165.0 & 25 & 120 \\
\hline & Dimethomorph (2) & 6.5 & 388.2 & 301.1 & 20 & 165.0 & 25 & 120 \\
\hline 63 & Dimethylvinphos & 6.8 & 331.0 & 127.0 & 15 & 170.1 & 47 & 90 \\
\hline 64 & Demeton-S-methyl & 4.9 & 231.1 & 89.1 & 2 & 61.1 & 30 & 50 \\
\hline 65 & Diniconazole & 8.6 & 326.1 & 70.1 & 25 & 159.0 & 30 & 120 \\
\hline 66 & Diphenamid & 5.7 & 240.2 & 134.1 & 20 & 167.0 & 20 & 100 \\
\hline 67 & Dithiopyr & 9.1 & 402.1 & 271.9 & 30 & 353.9 & 24 & 135 \\
\hline 68 & Diuron & 5.6 & 233.1 & 72.1 & 25 & 160.0 & 25 & 100 \\
\hline 69 & Dymron & 6.6 & 269.0 & 151.0 & 16 & 119.0 & 25 & 90 \\
\hline 70 & Edifenphos & 7.8 & 311.1 & 109.0 & 35 & 111.0 & 25 & 80 \\
\hline 71 & EPN & 8.8 & 324.1 & 157.1 & 20 & 295.9 & 12 & 50 \\
\hline 72 & Esprocarb & 9.7 & 266.2 & 91.1 & 20 & 65.1 & 79 & 110 \\
\hline 73 & Ethaboxam & 5.2 & 321.1 & 183.1 & 35 & 200.1 & 35 & 160 \\
\hline 74 & Ethiofencarb & 5.2 & 226.1 & 107.1 & 15 & 164.2 & 7 & 50 \\
\hline 75 & Ethofenprox & 12.7 & 394.3 & 177.2 & 21 & 135.1 & 33 & 100 \\
\hline 76 & Ethoprophos & 7.1 & 243.1 & 97.0 & 30 & 131.0 & 20 & 100 \\
\hline 77 & Ethoxyquin & 6.0 & 218.0 & 159.9 & 32 & 173.9 & 18 & 130 \\
\hline 78 & Ethoxysulfuron & 6.6 & 398.9 & 260.9 & 10 & 217.8 & 22 & 120 \\
\hline 79 & Etoxazole & 10.7 & 360.2 & 141.0 & 35 & 63.1 & 129 & 150 \\
\hline 80 & Etrimfos & 7.8 & 293.1 & 125.0 & 24 & 265.1 & 25 & 120 \\
\hline 81 & Famoxadone & 8.1 & 397.1 & 353.0 & 8 & 261.2 & 8 & 120 \\
\hline 82 & Fenamidone & 6.2 & 312.2 & 92.1 & 25 & 65.1 & 40 & 100 \\
\hline 83 & Fenamiphos & 7.4 & 304.2 & 217.0 & 20 & 202.0 & 40 & 110 \\
\hline 84 & Fenarimol & 7.0 & 331.1 & 268.0 & 25 & 81.0 & 30 & 120 \\
\hline 85 & Fenazaquin & 11.4 & 307.2 & 161.2 & 25 & 147.1 & 25 & 100 \\
\hline 86 & Fenbuconazole & 7.3 & 337.1 & 70.0 & 20 & 125.0 & 20 & 120 \\
\hline 87 & Fenhexamid & 7.1 & 302.1 & 97.2 & 20 & 55.2 & 40 & 134 \\
\hline 88 & Fenobucarb (BPMC) & 6.1 & 208.1 & 95.1 & 15 & 152.1 & 9 & 40 \\
\hline 89 & Fenothiocarb & 7.5 & 254.2 & 72.1 & 14 & 160.1 & 12 & 100 \\
\hline
\end{tabular}


Table 3. Continued

\begin{tabular}{|c|c|c|c|c|c|c|c|c|}
\hline No. & Pesticides & $\begin{array}{l}\text { Retention } \\
\text { time (min) }\end{array}$ & Parent ion & $\begin{array}{l}\text { Quantitative ion } \\
(\mathrm{m} / \mathrm{z})\end{array}$ & $\begin{array}{l}\text { Collision } \\
\text { energy (V) }\end{array}$ & $\begin{array}{l}\text { Qualitative ion } \\
(\mathrm{m} / \mathrm{z})\end{array}$ & $\begin{array}{l}\text { Collision } \\
\text { energy (V) }\end{array}$ & $\begin{array}{l}\text { Fragmentor } \\
\text { Voltage (V) }\end{array}$ \\
\hline \multirow[t]{2}{*}{90} & Fenoxanil (1) & 7.4 & 329.1 & 302.1 & 4 & 86.3 & 20 & 80 \\
\hline & Fenoxanil (2) & 7.5 & 329.1 & 302.1 & 4 & 86.3 & 20 & 80 \\
\hline 91 & Fenoxaprop-ethyl & 9.4 & 362.1 & 288.1 & 12 & 121.1 & 28 & 138 \\
\hline 92 & Fenoxycarb & 7.5 & 302.0 & 116.0 & 7 & 256.0 & 7 & 90 \\
\hline 93 & Fenpyroximate & 11.0 & 422.2 & 366.2 & 24 & 135.0 & 35 & 100 \\
\hline 94 & Fenthion (MPP) & 7.8 & 279.0 & 169.1 & 12 & 247.0 & 8 & 115 \\
\hline 95 & Fentrazamide & 7.9 & 350.0 & 83.0 & 20 & 154.0 & 8 & 80 \\
\hline 96 & Ferimzone & 5.9 & 255.2 & 124.1 & 30 & 132.1 & 30 & 120 \\
\hline 97 & Flomicamid & 3.6 & 230.0 & 203.0 & 14 & 148.0 & 30 & 100 \\
\hline 98 & luaxrypyrim & 8.8 & 427.2 & 145.1 & 25 & 205.1 & 5 & 100 \\
\hline 99 & Flubendiamide & 7.7 & 408.0 & 273.8 & 17 & 255.8 & 22 & 100 \\
\hline 100 & Flucetosulfuron & 6.0 & 488.1 & 156.0 & 16 & 273.0 & 24 & 125 \\
\hline 101 & Fludioxonil & 6.3 & 266.2 & 229.1 & 10 & 158.1 & 47 & 100 \\
\hline 102 & Flufenacet & 7.1 & 364.1 & 152.0 & 16 & 194.0 & 4 & 85 \\
\hline 103 & Flufenoxuron & 10.8 & 489.1 & 158.1 & 17 & 141.2 & 35 & 150 \\
\hline 104 & Flumioxazin & 5.8 & 355.1 & 299.1 & 32 & 327.0 & 32 & 135 \\
\hline 105 & Fluopiolide & 6.5 & 383.0 & 172.9 & 25 & 108.9 & 91 & 100 \\
\hline 106 & Fluopyram & 6.9 & 397.1 & 173.0 & 20 & 207.9 & 32 & 125 \\
\hline 107 & Fluquinconazole & 6.9 & 376.0 & 307.0 & 30 & 108.1 & 69 & 100 \\
\hline 108 & Flusilazole & 7.4 & 316.1 & 247.1 & 15 & 165.0 & 20 & 120 \\
\hline 109 & Flutolanil & 6.5 & 324.2 & 262.1 & 15 & 242.1 & 25 & 120 \\
\hline 110 & Forchlorfenuron & 5.6 & 248.1 & 129.1 & 18 & 155.1 & 19 & 100 \\
\hline 111 & Fosthiazate & 5.2 & 284.1 & 104.0 & 20 & 228.0 & 9 & 70 \\
\hline 112 & Furathiocarb & 9.6 & 383.2 & 195.1 & 10 & 252.0 & 10 & 100 \\
\hline 113 & Gibberrellic acid & 4.1 & 364.2 & 239.3 & 14 & 221.2 & 20 & 90 \\
\hline 114 & Halosulfuron-methyl & 6.8 & 434.9 & 182.1 & 10 & 139.1 & 50 & 120 \\
\hline 115 & Haloxyfop & 7.7 & 362.0 & 316.1 & 12 & 91.2 & 36 & 120 \\
\hline 116 & Hexaconazole & 8.2 & 314.1 & 70.1 & 20 & 159.1 & 20 & 120 \\
\hline 117 & Hexaflumuron & 9.1 & 461.0 & 158.0 & 20 & 141.0 & 48 & 134 \\
\hline 118 & Hexazinone & 4.9 & 253.2 & 171.0 & 12 & 71.1 & 36 & 100 \\
\hline 119 & Hexythiazox & 10.3 & 353.2 & 168.0 & 22 & 228.2 & 15 & 100 \\
\hline 120 & Imazalil & 5.3 & 297.1 & 159.0 & 30 & 69.1 & 30 & 100 \\
\hline 121 & Imazosulfuron & 6.3 & 413.1 & 152.9 & 8 & 156.0 & 16 & 110 \\
\hline 122 & Imibenconazole & 10.0 & 411.0 & 124.9 & 27 & 170.8 & 25 & 100 \\
\hline 123 & Imicyafos & 4.6 & 305.1 & 201.0 & 16 & 235.0 & 14 & 120 \\
\hline 124 & Imidacloprid & 3.9 & 256.1 & 175.1 & 20 & 209.1 & 20 & 100 \\
\hline 125 & Inabenfide & 6.2 & 339.1 & 321.0 & 12 & 80.0 & 32 & 125 \\
\hline 126 & Iprobenfos & 7.6 & 289.2 & 91.1 & 17 & 205.1 & 6 & 50 \\
\hline 127 & Iprovalicarb & 6.8 & 321.3 & 119.1 & 20 & 203.1 & 5 & 80 \\
\hline 128 & Isoprocarb (MIPC) & 5.4 & 194.2 & 95.1 & 10 & 137.1 & 10 & 70 \\
\hline 129 & Isoprothiolane & 6.5 & 291.1 & 189.0 & 15 & 231.1 & 12 & 70 \\
\hline 130 & Isopyrazam & 8.8 & 360.2 & 244.0 & 20 & 320.1 & 16 & 130 \\
\hline 131 & Kresoxim-methyl & 7.7 & 314.0 & 222.0 & 10 & 267.0 & 5 & 80 \\
\hline 132 & Linuron & 6.1 & 249.0 & 159.9 & 16 & 182.0 & 8 & 100 \\
\hline 133 & Lufenuron & 10.2 & 511.0 & 157.8 & 10 & 140.9 & 30 & 100 \\
\hline
\end{tabular}


Table 3. Continued

\begin{tabular}{|c|c|c|c|c|c|c|c|c|}
\hline No. & Pesticides & $\begin{array}{l}\text { Retention } \\
\text { time (min) }\end{array}$ & Parent ion & $\begin{array}{l}\text { Quantitative ion } \\
(\mathrm{m} / \mathrm{z})\end{array}$ & $\begin{array}{l}\text { Collision } \\
\text { energy (V) }\end{array}$ & $\begin{array}{l}\text { Qualitative ion } \\
(\mathrm{m} / \mathrm{z})\end{array}$ & $\begin{array}{l}\text { Collision } \\
\text { energy (V) }\end{array}$ & $\begin{array}{l}\text { Fragmentor } \\
\text { Voltage (V) }\end{array}$ \\
\hline 134 & Malathion & 6.5 & 331.0 & 127.0 & 5 & 99.0 & 10 & 80 \\
\hline 135 & Mandipripamid & 6.4 & 412.2 & 328.2 & 12 & 125.0 & 40 & 100 \\
\hline 136 & Mefenacet & 6.7 & 299.1 & 148.1 & 15 & 120.2 & 25 & 100 \\
\hline 137 & Mepanipyrim & 6.9 & 224.2 & 77.1 & 45 & 106.1 & 40 & 100 \\
\hline 138 & Mepronil & 6.6 & 270.2 & 119.0 & 20 & 91.0 & 45 & 100 \\
\hline 139 & Metalaxyl & 5.5 & 280.2 & 160.1 & 22 & 220.2 & 14 & 100 \\
\hline 140 & Metamifop & 9.5 & 441.1 & 288.0 & 22 & 180.1 & 22 & 150 \\
\hline 141 & Metazosulfuron & 6.1 & 476.1 & 182.1 & 20 & 295.1 & 10 & 110 \\
\hline 142 & Metconazole & 8.3 & 320.2 & 70.1 & 25 & 125.1 & 50 & 100 \\
\hline 143 & Methabenzthiazuron & 5.4 & 222.1 & 165.1 & 17 & 150.1 & 35 & 100 \\
\hline 144 & Methidathion & 5.7 & 303.0 & 85.0 & 15 & 145.0 & 10 & 70 \\
\hline 145 & Methiocarb & 6.2 & 226.1 & 169.1 & 5 & 121.1 & 10 & 80 \\
\hline 146 & Methomyl & 3.6 & 163.1 & 88.1 & 5 & 106.1 & 5 & 50 \\
\hline 147 & Methoxyfenozide & 6.5 & 369.2 & 149.1 & 13 & 133.1 & 15 & 100 \\
\hline 148 & Metobromuron & 5.4 & 259.0 & 170.0 & 18 & 148.2 & 18 & 100 \\
\hline 149 & Metolachlor & 7.3 & 284.2 & 252.2 & 15 & 176.1 & 25 & 100 \\
\hline 150 & Metolcarb & 4.6 & 166.1 & 109.1 & 10 & 94.1 & 25 & 50 \\
\hline 151 & Metrafenone & 8.5 & 40.91 & 209.0 & 8 & 226.9 & 16 & 105 \\
\hline 152 & Metribuzin & 4.9 & 215.1 & 187.2 & 28 & 60.0 & 53 & 100 \\
\hline \multirow[t]{2}{*}{153} & Mevinphos-1 & 4.1 & 225.1 & 127.1 & 10 & 193.1 & 0 & 50 \\
\hline & Mevinphos-2 & 4.3 & 225.1 & 127.1 & 10 & 193.1 & 0 & 50 \\
\hline \multirow[t]{2}{*}{154} & Milbemectin A3 & 12.0 & 511.3 & 95.0 & 30 & 105.0 & 60 & 100 \\
\hline & Milbemectin A4 & 12.6 & 525.4 & 55.2 & 80 & 91.0 & 114 & 120 \\
\hline 155 & Molinate & 6.7 & 188.1 & 55.1 & 25 & 126.1 & 10 & 120 \\
\hline 156 & Monocrotophos & 3.7 & 224.1 & 127.0 & 10 & 193.0 & 0 & 100 \\
\hline 157 & Myclobutanil & 6.7 & 289.2 & 70.1 & 27 & 125.0 & 27 & 100 \\
\hline 158 & Napropamide & 7.1 & 272.2 & 171.1 & 18 & 129.1 & 18 & 100 \\
\hline 159 & Nicosulfuron & 4.7 & 411.1 & 182.0 & 16 & 106.0 & 36 & 120 \\
\hline 160 & Novaluron & 9.3 & 493.0 & 158.2 & 16 & 141.2 & 52 & 90 \\
\hline 161 & Nuarimol & 6.1 & 315.1 & 81.0 & 30 & 251.9 & 25 & 120 \\
\hline 162 & Ofurace & 4.8 & 282.1 & 160.2 & 18 & 254.2 & 13 & 100 \\
\hline 163 & Omethoate & 2.0 & 214.0 & 125.0 & 20 & 183.0 & 5 & 80 \\
\hline 164 & Oxadiazon & 9.9 & 345.1 & 220.0 & 18 & 177.0 & 19 & 135 \\
\hline 165 & Oxadixyl & 4.5 & 279.1 & 219.0 & 32 & 177.0 & 4 & 75 \\
\hline 166 & Oxamyl & 3.2 & 237.1 & 72.1 & 10 & 90.1 & 10 & 80 \\
\hline 167 & Oxaziclomefon & 9.4 & 376.1 & 190.1 & 11 & 133 & 27 & 100 \\
\hline 168 & Paclobutrazole & 6.5 & 294.1 & 70.1 & 20 & 125.0 & 48 & 100 \\
\hline 169 & Penconazole & 7.8 & 284.1 & 70.1 & 20 & 159.0 & 39 & 80 \\
\hline 170 & Pencycuron & 8.6 & 329.0 & 125.0 & 24 & 89.0 & 60 & 100 \\
\hline 171 & Pendimethalin & 10.3 & 282.1 & 212.1 & 13 & 194.1 & 17 & 70 \\
\hline 172 & Penoxsulam & 5.0 & 484.1 & 195.0 & 28 & 164.0 & 36 & 160 \\
\hline 173 & Penthiopyrad & 7.8 & 360.1 & 275.9 & 8 & 177.0 & 36 & 110 \\
\hline 174 & Pentoxazone & 9.5 & 354.2 & 286.0 & 15 & 186.0 & 15 & 135 \\
\hline 175 & Phenthoate & 7.6 & 321.1 & 79.0 & 55 & 135.0 & 20 & 100 \\
\hline 176 & Phorate & 8.3 & 261.0 & 75.0 & 4 & 199.1 & 0 & 60 \\
\hline
\end{tabular}


Table 3. Continued

\begin{tabular}{|c|c|c|c|c|c|c|c|c|}
\hline No. & Pesticides & $\begin{array}{l}\text { Retention } \\
\text { time (min) }\end{array}$ & Parent ion & $\begin{array}{l}\text { Quantitative ion } \\
(\mathrm{m} / \mathrm{z})\end{array}$ & $\begin{array}{l}\text { Collision } \\
\text { energy (V) }\end{array}$ & $\begin{array}{l}\text { Qualitative ion } \\
\qquad(\mathrm{m} / \mathrm{z})\end{array}$ & $\begin{array}{l}\text { Collision } \\
\text { energy (V) }\end{array}$ & $\begin{array}{l}\text { Fragmentor } \\
\text { Voltage (V) }\end{array}$ \\
\hline 177 & Phosalone & 8.4 & 368.1 & 181.9 & 10 & 75.1 & 100 & 100 \\
\hline 178 & Phosphamidone & 4.5 & 300.1 & 127.0 & 20 & 174.1 & 17 & 120 \\
\hline 179 & Phoxim & 8.2 & 299.1 & 77.0 & 36 & 129.0 & 4 & 70 \\
\hline 180 & Picoxystrobin & 7.5 & 368.1 & 145.0 & 16 & 205.1 & 4 & 75 \\
\hline 181 & Piperophos & 8.8 & 354.1 & 171.0 & 20 & 255.1 & 12 & 90 \\
\hline 182 & Pirimicarb & 4.8 & 239.2 & 72.1 & 20 & 182.2 & 18 & 100 \\
\hline 183 & Pirimiphos-methyl & 8.3 & 306.2 & 108.1 & 22 & 164.1 & 32 & 100 \\
\hline 184 & Probenazole & 6.9 & 224.0 & 77.3 & 88 & 51.2 & 40 & 62 \\
\hline 185 & Prochloraz & 8.2 & 376.1 & 308.0 & 13 & 70.0 & 22 & 50 \\
\hline 186 & Profenofos & 9.4 & 373.0 & 302.9 & 15 & 127.9 & 50 & 90 \\
\hline 187 & Prometryn & 6.5 & 242.2 & 158.1 & 27 & 200.1 & 27 & 100 \\
\hline 188 & Propamocarb & 2.2 & 189.2 & 102.1 & 15 & 73.9 & 20 & 100 \\
\hline 189 & Propanil & 6.2 & 218.0 & 162.0 & 15 & 127.0 & 20 & 120 \\
\hline 190 & Propaquizafop & 9.8 & 444.1 & 100.0 & 12 & 56.1 & 36 & 115 \\
\hline 191 & Propiconazole & 8.0 & 342.1 & 159.0 & 20 & 69.0 & 20 & 120 \\
\hline 192 & Propoxur & 4.8 & 210.2 & 111.1 & 10 & 93.1 & 25 & 50 \\
\hline 193 & Pymetrozine & 1.9 & 218.1 & 105.2 & 20 & 79.0 & 30 & 110 \\
\hline 194 & Pyraclofos & 8.3 & 361.1 & 138.1 & 40 & 111.0 & 50 & 100 \\
\hline 195 & Pyraclostrobin & 8.2 & 388.1 & 194.1 & 10 & 163.1 & 20 & 120 \\
\hline 196 & Pyrazolate & 8.5 & 439.0 & 91.2 & 36 & 173.1 & 16 & 118 \\
\hline 197 & Pyrazophos & 8.4 & 374.1 & 222.1 & 20 & 194.1 & 30 & 120 \\
\hline 198 & Pyribenzoxim & 9.8 & 413.2 & 119.0 & 35 & 289.1 & 30 & 100 \\
\hline 199 & Pyributicarb & 10.1 & 331.2 & 108.0 & 30 & 181.1 & 19 & 70 \\
\hline 200 & Pyridaben & 11.6 & 365.2 & 147.1 & 18 & 309.2 & 13 & 100 \\
\hline 201 & Pyridaphenthion & 6.7 & 341.1 & 189.1 & 24 & 205.1 & 24 & 100 \\
\hline 202 & Pyrifluquinazon & 6.7 & 465.1 & 423.0 & 20 & 107.0 & 32 & 145 \\
\hline 203 & Pyriftalid & 5.9 & 319.1 & 139.0 & 28 & 179.0 & 32 & 155 \\
\hline 204 & Pyrimethanil & 6.0 & 200.1 & 77.1 & 50 & 181.1 & 43 & 100 \\
\hline 205 & Pyrimidifen & 9.6 & 378.1 & 184.1 & 27 & 150.0 & 45 & 150 \\
\hline \multirow[t]{2}{*}{206} & Pyriminobac-methyl $(E)$ & 6.4 & 362.2 & 330.2 & 10 & 284.1 & 30 & 100 \\
\hline & Pyriminobac-methyl $(Z)$ & 5.9 & 362.2 & 330.2 & 15 & 75 & 110 & 100 \\
\hline 207 & Pyrimisulfan & 5.6 & 420.1 & 369.9 & 16 & 254.8 & 24 & 100 \\
\hline 208 & Pyriproxyfen & 10.1 & 322.1 & 96.0 & 16 & 185.0 & 16 & 100 \\
\hline 209 & Pyroquilon & 4.7 & 174.1 & 117.0 & 41 & 130.0 & 41 & 100 \\
\hline 210 & Quinalphos & 7.6 & 299.1 & 96.9 & 32 & 163.0 & 24 & 110 \\
\hline 211 & Quinmerac & 4.1 & 222.0 & 203.9 & 8 & 141.0 & 36 & 95 \\
\hline 212 & Quinoclamine & 4.7 & 208.1 & 77.0 & 37 & 105.0 & 35 & 100 \\
\hline 213 & Quizalofop-ethyl & 9.4 & 373.1 & 298.9 & 16 & 162.9 & 36 & 145 \\
\hline 214 & Saflufenacil & 5.9 & 501.1 & 348.9 & 24 & 197.9 & 48 & 140 \\
\hline 215 & Sethoxydim & 9.7 & 328.2 & 282.2 & 4 & 178.1 & 16 & 116 \\
\hline 216 & Silafluofen & 14.8 & 426.1 & 287.2 & 0 & 168.1 & 34 & 90 \\
\hline 217 & Simeconazole & 7.1 & 294.1 & 73.0 & 25 & 134.9 & 25 & 100 \\
\hline 218 & Simetryn & 5.1 & 214.1 & 68.1 & 35 & 124.0 & 29 & 100 \\
\hline \multirow[t]{2}{*}{219} & Spinetoram (j) & 9.2 & 748.5 & 142.0 & 28 & 98.0 & 60 & 180 \\
\hline & Spinetoram (L) & 9.9 & 760.5 & 142.0 & 28 & 98.0 & 60 & 180 \\
\hline
\end{tabular}


Table 3. Continued

\begin{tabular}{|c|c|c|c|c|c|c|c|c|}
\hline No. & Pesticides & $\begin{array}{l}\text { Retention } \\
\text { time (min) }\end{array}$ & Parent ion & $\begin{array}{l}\text { Quantitative ion } \\
(\mathrm{m} / \mathrm{z})\end{array}$ & $\begin{array}{l}\text { Collision } \\
\text { energy (V) }\end{array}$ & $\begin{array}{l}\text { Qualitative ion } \\
(\mathrm{m} / \mathrm{z})\end{array}$ & $\begin{array}{l}\text { Collision } \\
\text { energy (V) }\end{array}$ & $\begin{array}{l}\text { Fragmentor } \\
\text { Voltage (V) }\end{array}$ \\
\hline 220 & Spirodiclofen & 11.1 & 411.2 & 71.0 & 10 & 313.1 & 10 & 120 \\
\hline 221 & Spiromesifen & 10.6 & 371.1 & 273.1 & 15 & 255.0 & 19 & 40 \\
\hline 222 & Sulfoxaflor & 4.2 & 278.1 & 174.2 & 4 & 154.2 & 28 & 50 \\
\hline 223 & Tebuconazole & 7.9 & 308.2 & 70.0 & 20 & 125.0 & 30 & 120 \\
\hline 224 & Tebufenozide & 7.5 & 297.0 & 133.0 & 10 & 104.9 & 18 & 100 \\
\hline 225 & Tebufenpyrad & 9.7 & 334.1 & 117.0 & 37 & 145.0 & 37 & 150 \\
\hline 226 & Tebupirimfos & 9.8 & 319.0 & 153.1 & 30 & 277.0 & 18 & 100 \\
\hline 227 & Teflubenzuron & 9.9 & 381.2 & 141.1 & 30 & 158.0 & 12 & 100 \\
\hline 228 & Terbuthylazine & 6.3 & 230.1 & 174.1 & 15 & 104.0 & 35 & 120 \\
\hline 229 & Terbutryn & 6.6 & 242.1 & 186.1 & 15 & 71.0 & 20 & 120 \\
\hline 230 & Tetraconazole & 7.1 & 371.9 & 159.0 & 28 & 70.0 & 28 & 120 \\
\hline 231 & Thenylchlor & 7.0 & 324.1 & 127.0 & 4 & 97.0 & 48 & 70 \\
\hline 232 & Thiabendazole & 3.9 & 202.0 & 131.1 & 40 & 175.0 & 30 & 120 \\
\hline 233 & Thiacloprid & 4.2 & 253.0 & 126.0 & 20 & 186.0 & 10 & 90 \\
\hline 234 & Thiamethoxam & 3.7 & 292.0 & 211.0 & 10 & 181.1 & 20 & 80 \\
\hline 235 & Thiazopyr & 7.8 & 397.2 & 377.1 & 20 & 355.1 & 28 & 170 \\
\hline 236 & Thidiazuron & 4.8 & 221.0 & 102.0 & 12 & 127.8 & 12 & 107 \\
\hline 237 & Thifensulfuron-methyl & 4.6 & 388.0 & 167.0 & 10 & 204.9 & 25 & 110 \\
\hline 238 & Thiobencarb & 8.5 & 258.1 & 125.0 & 13 & 89.1 & 67 & 50 \\
\hline 239 & Thiodicarb & 5.0 & 355.1 & 88.0 & 15 & 108.0 & 10 & 80 \\
\hline 240 & Thiophanate-methyl & 4.7 & 343.1 & 151.0 & 16 & 93.1 & 50 & 96 \\
\hline 241 & Triadinil & 6.8 & 268.0 & 100.7 & 20 & 101.2 & 20 & 50 \\
\hline 242 & Toclofos-methyl & 8.3 & 301.0 & 125.0 & 15 & 175.0 & 24 & 110 \\
\hline 243 & Tolylfluanid & 9.8 & 371.1 & 73.1 & 20 & 355 & 12 & 120 \\
\hline 244 & Triadimefon & 6.6 & 294.1 & 69.0 & 15 & 197.0 & 20 & 120 \\
\hline 245 & Triazophos & 6.8 & 314.1 & 162.1 & 17 & 119.0 & 35 & 100 \\
\hline 246 & Tricyclazole & 4.4 & 190.1 & 136.0 & 42 & 163.1 & 42 & 120 \\
\hline 247 & Trifloxystrobin & 9.0 & 409.2 & 186.1 & 14 & 206.1 & 14 & 100 \\
\hline 248 & Triflumizole & 9.0 & 346.1 & 73.1 & 11 & 278.1 & 11 & 100 \\
\hline 249 & Triflumuron & 8.3 & 359.1 & 155.9 & 16 & 138.9 & 40 & 90 \\
\hline 250 & Uniconazole & 7.3 & 292.2 & 70.1 & 22 & 125.0 & 30 & 110 \\
\hline 251 & Vamidothion & 4.0 & 288.1 & 146.0 & 4 & 118.0 & 20 & 85 \\
\hline
\end{tabular}

Table 4. Parameters for 110 pesticide residue analysis by GC-MS/MS

\begin{tabular}{llcccccc}
\hline No. & \multicolumn{1}{c}{ Pesticides } & $\begin{array}{c}\text { Retention time } \\
(\mathrm{min})\end{array}$ & Parent ion & $\begin{array}{c}\text { Quantitative ion } \\
(\mathrm{m} / \mathrm{z})\end{array}$ & $\begin{array}{c}\text { Collision } \\
\text { energy (V) }\end{array}$ & $\begin{array}{c}\text { Qualitative ion } \\
(\mathrm{m} / \mathrm{z})\end{array}$ & $\begin{array}{c}\text { Collision } \\
\text { energy (V) }\end{array}$ \\
\hline 1 & Acrinathrin-1 & 24.862 & 290 & 93 & 20 & 95 & 20 \\
& Acrinathrin-2 & 25.060 & 290 & 93 & 20 & 95 & 20 \\
2 & Alachlor & 17.976 & 188 & 160 & 15 & 131 & 15 \\
3 & Aldrin & 19.005 & 263 & 193 & 30 & 228 & 30 \\
4 & Anilofos & 24.726 & 226 & 157 & 10 & 184 & 10 \\
5 & BHC (alpha) & 15.254 & 181 & 145 & 25 & 109 & 25 \\
& BHC (beta) & 15.983 & 181 & 145 & 25 & 109 & 25 \\
& BHC (delta) & 16.960 & 181 & 145 & 25 & 109 & 25 \\
& BHC (gamma) & 16.188 & 181 & 145 & 25 & & 109 \\
\hline
\end{tabular}


Table 4. Continued

\begin{tabular}{|c|c|c|c|c|c|c|c|}
\hline No. & Pesticides & $\begin{array}{l}\text { Retention time } \\
\text { (min) }\end{array}$ & Parent ion & $\begin{array}{l}\text { Quantitative ion } \\
(\mathrm{m} / \mathrm{z})\end{array}$ & $\begin{array}{l}\text { Collision } \\
\text { energy (V) }\end{array}$ & $\begin{array}{l}\text { Qualitative ion } \\
\qquad(\mathrm{m} / \mathrm{z})\end{array}$ & $\begin{array}{l}\text { Collision } \\
\text { energy }(V)\end{array}$ \\
\hline 6 & Bifenox & 24.759 & 341 & 189 & 15 & 281 & 15 \\
\hline 7 & Bifenthrin & 24.380 & 181 & 166 & 15 & 167 & 15 \\
\hline 8 & Bromobutide & 17.749 & 119 & 91 & 30 & 65 & 15 \\
\hline 9 & Bromoproylate & 24.411 & 341 & 185 & 10 & 183 & 10 \\
\hline 10 & Butachlor & 20.770 & 176 & 147 & 15 & 134 & 15 \\
\hline 11 & Captan & 20.189 & 149 & 105 & 10 & 79 & 10 \\
\hline 12 & Cabofuran & 6.586 & 164 & 149 & 10 & 103 & 25 \\
\hline 13 & Carbophenothion & 22.974 & 342 & 157 & 10 & 296 & 5 \\
\hline 14 & Chinomethionat & 20.566 & 234 & 206 & 15 & 148 & 10 \\
\hline \multirow[t]{2}{*}{15} & Chlordane (cis) & 20.864 & 375 & 266 & 15 & 301 & 15 \\
\hline & Chlordane (trans) & 20.547 & 375 & 266 & 15 & 301 & 15 \\
\hline 16 & Chlorfenapyr & 21.806 & 247 & 227 & 30 & 200 & 30 \\
\hline \multirow[t]{2}{*}{17} & Chlorfenvinphos (cis) & 20.044 & 267 & 159 & 15 & 203 & 15 \\
\hline & Chlorfenvinphos (trans) & 19.795 & 267 & 159 & 15 & 203 & 15 \\
\hline 18 & Chlorfluazuron & 17.553 & 321 & 304 & 20 & 286 & 15 \\
\hline 19 & Chlorobenzilate & 22.184 & 251 & 111 & 30 & 139 & 30 \\
\hline 20 & Chlorothalonil & 16.639 & 266 & 231 & 15 & 133 & 35 \\
\hline 21 & Chlorpropham & 14.682 & 213 & 127 & 10 & 171 & 10 \\
\hline 22 & Chlorpyrifos-methyl & 17.764 & 286 & 93 & 20 & 271 & 10 \\
\hline 23 & Cyflufenamid & 18.389 & 412 & 223 & 15 & 294 & 10 \\
\hline \multirow[t]{4}{*}{24} & Cyfluthrin-1 & 27.220 & 206 & 151 & 25 & 177 & 25 \\
\hline & Cyfluthrin-2 & 27.350 & 206 & 151 & 25 & 177 & 25 \\
\hline & Cyfluthrin-3 & 27.420 & 206 & 151 & 25 & 177 & 25 \\
\hline & Cyfluthrin-4 & 27.480 & 206 & 151 & 25 & 177 & 25 \\
\hline \multirow[t]{2}{*}{25} & Cyhalothrin-1 & 25.370 & 197 & 141 & 5 & 161 & 5 \\
\hline & Cyhalothrin-2 & 25.590 & 197 & 141 & 5 & 161 & 5 \\
\hline \multirow[t]{4}{*}{26} & Cypermethrin-1 & 27.620 & 181 & 127 & 30 & 152 & 25 \\
\hline & Cypermethrin-2 & 27.750 & 181 & 127 & 30 & 152 & 25 \\
\hline & Cypermethrin-3 & 27.820 & 181 & 127 & 30 & 152 & 25 \\
\hline & Cypermethrin-4 & 27.870 & 181 & 127 & 30 & 152 & 25 \\
\hline 27 & Cyprodinil & 19.806 & 224 & 208 & 25 & 224 & 10 \\
\hline \multirow[t]{4}{*}{28} & o,p-DDT & 22.390 & 235 & 165 & 15 & 199 & 15 \\
\hline & $\mathrm{p}, \mathrm{p}-\mathrm{DDD}$ & 22.389 & 235 & 165 & 15 & 199 & 15 \\
\hline & $\mathrm{p}, \mathrm{p}-\mathrm{DDE}$ & 22.184 & 246 & 176 & 20 & 211 & 20 \\
\hline & $\mathrm{p}, \mathrm{p}-\mathrm{DDT}$ & 23.262 & 235 & 165 & 15 & 200 & 10 \\
\hline 29 & Deltamethrin & 26.128 & 253 & 93 & 20 & 172 & 10 \\
\hline 30 & Dichlofluanid & 15.352 & 224 & 77 & 15 & 123 & 10 \\
\hline 31 & Diclofop-methyl & 23.605 & 253 & 162 & 15 & 190 & 15 \\
\hline 32 & Dicloran & 15.628 & 206 & 148 & 20 & 176 & 20 \\
\hline 33 & Dicofol & 19.327 & 139 & 75 & 25 & 111 & 25 \\
\hline 34 & Dieldrin & 21.506 & 263 & 193 & 30 & 228 & 20 \\
\hline 35 & Dimethoate & 15.639 & 125 & 79 & 20 & 93 & 20 \\
\hline 36 & Dimethylvinphos & 19.021 & 295 & 109 & 15 & 295 & 15 \\
\hline 37 & Diphenylamine & 14.162 & 169 & 115 & 40 & 139 & 40 \\
\hline 38 & Disulfoton & 16.814 & 142 & 81 & 15 & 109 & 10 \\
\hline
\end{tabular}


Table 4. Continued

\begin{tabular}{|c|c|c|c|c|c|c|c|}
\hline No. & Pesticides & $\begin{array}{l}\text { Retention time } \\
\text { (min) }\end{array}$ & Parent ion & $\begin{array}{l}\text { Quantitative ion } \\
(\mathrm{m} / \mathrm{z})\end{array}$ & $\begin{array}{l}\text { Collision } \\
\text { energy (V) }\end{array}$ & $\begin{array}{l}\text { Qualitative ion } \\
(\mathrm{m} / \mathrm{z})\end{array}$ & $\begin{array}{c}\text { Collision } \\
\text { energy (V) }\end{array}$ \\
\hline \multirow[t]{3}{*}{39} & Endosulfan (alpha) & 20.862 & 241 & 206 & 15 & 170 & 25 \\
\hline & Endosulfan (beta) & 22.243 & 241 & 206 & 15 & 170 & 25 \\
\hline & Endosulfan-sulfate & 22.394 & 272 & 237 & 15 & 143 & 25 \\
\hline 40 & Endrin & 21.981 & 263 & 193 & 30 & 228 & 15 \\
\hline 41 & EPN & 24.373 & 157 & 77 & 20 & 110 & 15 \\
\hline 42 & Ethalfuralin & 14.579 & 276 & 202 & 10 & 248 & 5 \\
\hline 43 & Ethion & 23.141 & 272 & 237 & 20 & 119 & 25 \\
\hline 44 & Etridiazole & 8.690 & 211 & 183 & 10 & 140 & 20 \\
\hline 45 & Fenamidone & 24.611 & 238 & 103 & 30 & 238 & 30 \\
\hline 46 & Fenamiphos & 21.042 & 303 & 154 & 25 & 288 & 10 \\
\hline 47 & Fenitrothion & 18.561 & 277 & 109 & 20 & 260 & 10 \\
\hline 48 & Fenothiocarb & 20.777 & 160 & 72 & 15 & 160 & 5 \\
\hline 49 & Fenpropathrin & 24.591 & 265 & 181 & 20 & 210 & 10 \\
\hline \multirow[t]{2}{*}{50} & Fenvalerate-1 & 28.700 & 225 & 119 & 15 & 147 & 15 \\
\hline & Fenvalerate-2 & 28.950 & 225 & 119 & 15 & 147 & 15 \\
\hline 51 & Ferimzone $(E, Z)$ & 20.431 & 239 & 107 & 10 & 82 & 10 \\
\hline 52 & Fipronil & 19.924 & 367 & 213 & 30 & 255 & 20 \\
\hline \multirow[t]{2}{*}{53} & Flucyrhrinate-1 & 27.819 & 199 & 157 & 15 & 107 & 15 \\
\hline & Flucyrhrinate-2 & 28.070 & 199 & 157 & 15 & 107 & 15 \\
\hline 54 & Fludioxonil & 21.204 & 248 & 154 & 10 & 182 & 10 \\
\hline 55 & Fluopyram & 16.681 & 396 & 223 & 10 & 173 & 10 \\
\hline 56 & Folpet & 20.332 & 260 & 130 & 10 & 232 & 10 \\
\hline 57 & Fthalide & 19.362 & 272 & 215 & 25 & 243 & 25 \\
\hline 58 & Halfenprox & 27.688 & 263 & 235 & 15 & 115 & 20 \\
\hline \multirow[t]{2}{*}{59} & Heptachlor & 18.106 & 272 & 235 & 15 & 237 & 15 \\
\hline & Heptachlor-epoxide & 19.970 & 353 & 263 & 15 & 282 & 15 \\
\hline 60 & Imazalil & 21.195 & 215 & 145 & 25 & 173 & 25 \\
\hline 61 & Indanofan & 24.704 & 174 & 131 & 20 & 159 & 20 \\
\hline 62 & Indoxacarb & 29.425 & 218 & 134 & 20 & 203 & 20 \\
\hline 63 & Iprodione & 24.171 & 314 & 245 & 15 & 271 & 10 \\
\hline 64 & Isofenphos & 20.005 & 213 & 121 & 15 & 185 & 10 \\
\hline 65 & Lufenuron & 10.586 & 353 & 203 & 5 & 174 & 25 \\
\hline 66 & Mecarbam & 20.105 & 131 & 86 & 15 & 74 & 15 \\
\hline 67 & Methidation & 20.499 & 145 & 85 & 5 & 58 & 15 \\
\hline \multirow[t]{3}{*}{68} & Methoxychlor 1 & 20.115 & 227 & 169 & 25 & 212 & 15 \\
\hline & Methoxychlor 2 & 21.076 & 227 & 169 & 25 & 212 & 15 \\
\hline & Methoxychlor & 24.534 & 227 & 169 & 25 & 212 & 15 \\
\hline 69 & Metobromuron & 17.404 & 170 & 143 & 25 & 91 & 50 \\
\hline 70 & Metolachlor & 18.920 & 162 & 134 & 10 & 133 & 10 \\
\hline 71 & Metribuzin & 17.767 & 198 & 82 & 15 & 110 & 10 \\
\hline 72 & Mevinphos & 10.723 & 192 & 127 & 10 & 164 & 10 \\
\hline 73 & Novaluron & 7.367 & 168 & 140 & 15 & 112 & 20 \\
\hline 74 & Oxyfluorfen & 21.572 & 361 & 252 & 20 & 300 & 20 \\
\hline 75 & Parathion & 19.161 & 291 & 109 & 15 & 137 & 10 \\
\hline 76 & Parathion-methyl & 17.917 & 263 & 109 & 10 & 246 & 5 \\
\hline
\end{tabular}


Table 4. Continued

\begin{tabular}{|c|c|c|c|c|c|c|c|}
\hline No. & Pesticides & $\begin{array}{l}\text { Retention time } \\
\text { (min) }\end{array}$ & Parent ion & $\begin{array}{l}\text { Quantitative ion } \\
\qquad(\mathrm{m} / \mathrm{z})\end{array}$ & $\begin{array}{l}\text { Collision } \\
\text { energy (V) }\end{array}$ & $\begin{array}{l}\text { Qualitative ion } \\
\qquad(\mathrm{m} / \mathrm{z})\end{array}$ & $\begin{array}{l}\text { Collision } \\
\text { energy }(V)\end{array}$ \\
\hline 77 & Pendimethalin & 19.784 & 252 & 162 & 10 & 191 & 10 \\
\hline 78 & Penthiopyrad & 18.889 & 302 & 152 & 5 & 302 & 5 \\
\hline \multirow[t]{2}{*}{79} & Permethrin-1 & 26.560 & 183 & 153 & 10 & 168 & 10 \\
\hline & Permethrin-2 & 26.715 & 183 & 153 & 10 & 168 & 10 \\
\hline 80 & Phorate & 15.177 & 260 & 75 & 5 & 231 & 5 \\
\hline 81 & Picoxystrobin & 17.510 & 335 & 173 & 10 & 303 & 10 \\
\hline 82 & Pirimiphos-ethyl & 19.538 & 333 & 163 & 10 & 180 & 10 \\
\hline \multirow[t]{2}{*}{83} & Probenazole-1 & 12.961 & 130 & 77 & 20 & 103 & 20 \\
\hline & Probenazole-2 & 15.530 & 130 & 77 & 20 & 103 & 20 \\
\hline 84 & Procymidone & 20.263 & 283 & 96 & 10 & 67 & 25 \\
\hline 85 & Prometryn & 18.256 & 241 & 184 & 10 & 226 & 10 \\
\hline \multirow[t]{2}{*}{86} & Propiconazole-1 & 23.090 & 259 & 69 & 10 & 191 & 10 \\
\hline & Propiconazole-2 & 23.240 & 259 & 69 & 10 & 191 & 10 \\
\hline 87 & Prothiofos & 21.204 & 267 & 221 & 20 & 239 & 20 \\
\hline 88 & Pyridalyl & 28.055 & 204 & 148 & 20 & 176 & 20 \\
\hline 89 & Pyridaphenthion & 24.137 & 340 & 199 & 10 & 109 & 20 \\
\hline 90 & Quinoclamine & 18.794 & 207 & 172 & 10 & 144 & 20 \\
\hline \multirow[t]{3}{*}{91} & Quintozene & 16.053 & 237 & 143 & 20 & 117 & 20 \\
\hline & Methyl Pentachlorophenyl sulfide & 18.638 & 296 & 263 & 20 & 246 & 20 \\
\hline & Pentachloroanilline & 17.362 & 265 & 193 & 20 & 229 & 10 \\
\hline 92 & Silafluofen & 28.178 & 179 & 151 & 10 & 286 & 20 \\
\hline 93 & Simazine & 15.889 & 201 & 173 & 5 & 186 & 5 \\
\hline 94 & Simeconazole & 17.962 & 211 & 121 & 10 & 195 & 10 \\
\hline 95 & Simetryn & 18.067 & 213 & 170 & 10 & 185 & 10 \\
\hline 96 & Spiromesifen & 23.980 & 272 & 209 & 15 & 254 & 10 \\
\hline 97 & Tebupirimfos & 17.205 & 261 & 137 & 15 & 153 & 15 \\
\hline 98 & Tefluthrin & 17.010 & 177 & 127 & 10 & 157 & 10 \\
\hline 99 & Terbufos & 16.362 & 231 & 175 & 15 & 157 & 20 \\
\hline 100 & Terbutryn & 18.549 & 185 & 170 & 10 & 111 & 20 \\
\hline 101 & Tetradifon & 24.999 & 159 & 131 & 10 & 111 & 25 \\
\hline 102 & Thiazopyr & 18.882 & 327 & 263 & 30 & 277 & 30 \\
\hline 103 & Thifluzamide & 21.466 & 194 & 125 & 25 & 166 & 15 \\
\hline 104 & Tolclofos-methyl & 17.943 & 265 & 250 & 15 & 93 & 20 \\
\hline 105 & Tolyfluanid & 19.994 & 238 & 137 & 15 & 110 & 25 \\
\hline 106 & Tralomethrin & 29.595 & 253 & 172 & 10 & 199 & 25 \\
\hline 107 & Triadimenol & 20.270 & 168 & 70 & 10 & 112 & 10 \\
\hline 108 & Trifluralin & 14.854 & 306 & 264 & 10 & 160 & 25 \\
\hline 109 & Vinclozolin & 17.873 & 212 & 145 & 20 & 172 & 20 \\
\hline 110 & Zoxamide & 23.912 & 187 & 159 & 20 & 123 & 20 \\
\hline
\end{tabular}

하여 얻은 크로마토그램을 기초로 하여 $\mathrm{LOD}$ 는 $\mathrm{S} / \mathrm{N}$ ratio가 3 이상, $\mathrm{LOQ}$ 는 $\mathrm{S} / \mathrm{N}$ ratio 10 이상을 기준으로 측 정하였다.

\section{결과 및 고찰}

\section{검출한계 및 정량한계}

분석을 위한 검출한계(limit of detection, LOD) 및 정량 
Table 5. Average recovery and RSD of 251 pesticides spiked in apple and rice at two different concentrations with LC-MS/MS ( $\mathrm{n}=3$ )

\begin{tabular}{|c|c|c|c|c|c|c|c|}
\hline \multirow[t]{2}{*}{ No. } & \multirow[t]{2}{*}{ Compound } & \multirow{2}{*}{$\begin{array}{c}\text { LOD } \\
(\mu \mathrm{g} / \mathrm{kg})\end{array}$} & \multirow{2}{*}{$\begin{array}{c}\text { LOQ } \\
(\mu \mathrm{g} / \mathrm{kg})\end{array}$} & \multicolumn{2}{|c|}{$\begin{array}{c}\text { Recovery, \% (RSD, \%) } \\
\text { Apple }\end{array}$} & \multicolumn{2}{|c|}{$\begin{array}{c}\text { Recovery, \% (RSD, \%) } \\
\text { Rice }\end{array}$} \\
\hline & & & & $50 \mu \mathrm{g} / \mathrm{kg}$ & $200 \mu \mathrm{g} / \mathrm{kg}$ & $50 \mu \mathrm{g} / \mathrm{kg}$ & $200 \mu \mathrm{g} / \mathrm{kg}$ \\
\hline 1 & Abamectin B1 & 3 & 5 & $91.3(5.9)$ & $101.3(2.8)$ & $59.7(9.7)$ & $92.1(5.4)$ \\
\hline 2 & Acephate & 0.1 & 0.5 & $93.1(5.6)$ & $93.4(0.8)$ & $84.3(2.3)$ & $94.5(1.2)$ \\
\hline 3 & Acetamiprid & 0.01 & 0.05 & $114.9(2.7)$ & $99.3(1.1)$ & $78.0(3.7)$ & $108.0(0.5)$ \\
\hline 4 & Acibenzolar-S-methyl & 3 & 5 & $101.7(13.4)$ & $94.7(5.4)$ & $81.2(6.8)$ & $111.5(5.6)$ \\
\hline 5 & Alachlor ${ }^{*}$ & 5 & 10 & $110.4(1.7)$ & $92.3(0.7)$ & 83.3(13.8) & $100.2(8.3)$ \\
\hline 6 & Aldicarb & 0.01 & 0.05 & $105.8(1.2)$ & $99.3(0.9)$ & $94.0(5.9)$ & $105.1(3.6)$ \\
\hline 7 & Ametoctrdin & 0.03 & 0.05 & $100.1(1.1)$ & $98.5(0.9)$ & $89.2(6.1)$ & $101.7(3.2)$ \\
\hline 8 & Amisulbrom & 1 & 2 & $87.2(9.9)$ & $99.6(0.4)$ & $92.4(4.8)$ & $99.9(2.9)$ \\
\hline 9 & Amitraz & 0.03 & 0.05 & $2.56(11.8)$ & $1.36(8.9)$ & $72.3(2.4)$ & $64.5(10.0)$ \\
\hline 10 & Azimsulfuron & 0.03 & 0.05 & $109.6(4.8)$ & $102.3(3.3)$ & $89.5(9.1)$ & $93.4(9.4)$ \\
\hline 11 & Azinphos-methyl & 0.1 & 0.5 & $104.1(3.1)$ & $95.7(3.0)$ & $93.0(3.5)$ & $100.6(2.6)$ \\
\hline 12 & Azoxystrobin & 0.05 & 0.1 & $101.6(2.9)$ & $97.8(0.8)$ & $83.3(1.4)$ & $101.7(1.1)$ \\
\hline 13 & Bendiocarb & 0.05 & 0.5 & $112.6(3.7)$ & $99.6(1.8)$ & 83.7(3.6.) & $110.2(0.8)$ \\
\hline 14 & Benfuracarb & 0.03 & 0.05 & - & - & - & $1.7(58.5)$ \\
\hline 15 & Benfuresate & 0.005 & 0.01 & $115.7(1.7)$ & $94.1(4.3)$ & $442.8(39.0)$ & $165.4(18.5)$ \\
\hline 16 & Bensulfuron-methyl & 0.01 & 0.05 & 109.3(2.8) & $107.5(0.4)$ & $83.9(2.5)$ & $94.7(9.4)$ \\
\hline 17 & Benthiavalicarb-Isopropyl & 0.05 & 0.1 & $105.6(3.3)$ & $95.6(1.4)$ & $86.4(5.1)$ & $104.7(2.5)$ \\
\hline 18 & Benzobicyclon & 0.03 & 0.05 & $96.0(8.7)$ & $85.5(2.1)$ & $82.3(3.2)$ & $92.8(8.7)$ \\
\hline 19 & Benzoximate & 0.05 & 0.1 & $102.7(0.8)$ & $101.8(1.1)$ & 91.3(1.9) & $104.2(0.3)$ \\
\hline 20 & Bifenazate & 0.005 & 0.01 & $35.0(2.7)$ & $33.6(1.8)$ & $69.8(3.0)$ & $80.1(2.5)$ \\
\hline 21 & Bitertanol & 0.5 & 1 & $97.5(3.1)$ & $95.4(1.0)$ & $104.5(4.9)$ & $96.1(2.9)$ \\
\hline 22 & Boscalid & 0.1 & 0.5 & $106.1(6.0)$ & $102.0(0.2)$ & $84.9(8.9)$ & 108.9(1.6) \\
\hline 23 & Bromacil & 0.005 & 0.01 & 103.3(3.9) & $106.4(1.0)$ & $86.6(2.0)$ & 118.1(1.8) \\
\hline 24 & Buprofezin & 0.01 & 0.05 & $100.8(5.6)$ & $96.8(2.6)$ & $83.8(2.0)$ & 101.2(1.5) \\
\hline 25 & Cadusafos & 0.05 & 0.1 & $102.3(2.8)$ & $92.7(1.8)$ & $92.6(1.7)$ & 101.3(1.9) \\
\hline 26 & Cafenstrole & 0.03 & 0.05 & $110.2(5.1)$ & $100.1(2.4)$ & $81.1(4.1)$ & $110.5(2.0)$ \\
\hline 27 & Carbaryl(NAC) & 0.05 & 0.1 & 105.6(3.2) & $97.9(1.6)$ & $86.9(2.5)$ & 113.3(1.7) \\
\hline 28 & Carbendazim & 0.01 & 0.05 & $93.8(2.2)$ & $90.6(0.4)$ & $77.0(0.4)$ & $92.3(0.3)$ \\
\hline 29 & Carbofuran ${ }^{*}$ & 0.05 & 0.1 & $104.0(5.7)$ & $93.9(0.8)$ & $83.7(1.8)$ & $97.0(0.9)$ \\
\hline 30 & Carboxin & 0.03 & 0.05 & $91.0(1.7)$ & $90.2(0.8)$ & $86.4(1.8)$ & $110.7(1.0)$ \\
\hline 31 & Carfentrazone-ethyl & 0.008 & 0.01 & $160.3(3.2)$ & $102.6(1.0)$ & $91.5(3.4)$ & $104.1(1.0)$ \\
\hline 32 & Carpropamide & 0.01 & 0.05 & $103.6(2.0)$ & $100.7(1.2)$ & $77.4(6.4)$ & 107.8(0.9) \\
\hline 33 & Chlorantraniliprole & 0.5 & 1 & $99.1(5.2)$ & $98.0(1.5)$ & $91.7(5.2)$ & $100.4(1.2)$ \\
\hline 34 & Chlorfluazuron ${ }^{*}$ & 0.05 & 0.5 & $78.8(2.2)$ & $76.0(1.4)$ & $73.7(2.8)$ & $81.2(6.6)$ \\
\hline 35 & Chlorpyrifos & 1 & 2 & $93.4(1.1)$ & $92.1(4.6)$ & $91.3(1.8)$ & $98.6(1.2)$ \\
\hline 36 & Chlorsulfuron & 0.1 & 0.5 & $107.6(3.7)$ & $117.4(1.9)$ & 89.1(1.6) & $91.1(1.4)$ \\
\hline 37 & Chromafenozide & 0.05 & 0.1 & $105.9(3.1)$ & $100.7(0.9)$ & $92.1(3.3)$ & $106.4(1.2)$ \\
\hline 38 & Clethodim & 0.05 & 0.5 & $101.5(0.9)$ & $102.8(1.3)$ & $79.6(2.5)$ & $85.3(4.1)$ \\
\hline 39 & Clofentezine & 0.5 & 1 & $105.1(5.1)$ & $107.3(1.2)$ & $97.2(6.2)$ & $115.1(2.1)$ \\
\hline 40 & Clomazone & 0.03 & 0.05 & $100.7(4.2)$ & $94.9(0.6)$ & $85.0(3.3)$ & $105.8(1.0)$ \\
\hline 41 & Clothianidin & 0.1 & 1 & $80.7(4.0)$ & $85.6(3.1)$ & $86.4(3.8)$ & $100.8(3.8)$ \\
\hline 42 & Cyazofamid & 0.05 & 0.1 & $113.5(0.4)$ & $109.9(0.9)$ & $100.1(1.8)$ & $117.0(0.5)$ \\
\hline 43 & Cyclosulfamuron & 0.01 & 0.05 & $98.3(4.8)$ & $88.8(1.9)$ & $87.0(0.6)$ & $95.3(4.5)$ \\
\hline 44 & Cyflufenamid & 0.1 & 0.5 & $104.6(1.7)$ & $99.9(0.1)$ & $76.1(10.0)$ & 108.9(0.9) \\
\hline
\end{tabular}


Table 5. Continued

\begin{tabular}{|c|c|c|c|c|c|c|c|}
\hline \multirow[t]{2}{*}{ No. } & \multirow[t]{2}{*}{ Compound } & \multirow{2}{*}{$\begin{array}{c}\text { LOD } \\
(\mu \mathrm{g} / \mathrm{kg})\end{array}$} & \multirow{2}{*}{$\begin{array}{c}\text { LOQ } \\
(\mu \mathrm{g} / \mathrm{kg})\end{array}$} & \multicolumn{2}{|c|}{$\begin{array}{c}\text { Recovery, \% (RSD, \%) } \\
\text { Apple }\end{array}$} & \multicolumn{2}{|c|}{$\begin{array}{c}\text { Recovery, \% (RSD, \%) } \\
\text { Rice }\end{array}$} \\
\hline & & & & $50 \mu \mathrm{g} / \mathrm{kg}$ & $200 \mu \mathrm{g} / \mathrm{kg}$ & $50 \mu \mathrm{g} / \mathrm{kg}$ & $200 \mu \mathrm{g} / \mathrm{kg}$ \\
\hline 45 & Cyhalofop-butyl & 5 & 25 & $91.7(7.9)$ & $91.2(10.2)$ & $90.4(2.8)$ & $98.3(2.3)$ \\
\hline 46 & Cymoxanil* & 0.05 & 0.1 & $101.5(3.0)$ & $96.2(1.7)$ & $82.6(3.0)$ & $106.2(1.2)$ \\
\hline 47 & Cyproconazole & 0.5 & 1 & $99.3(1.3)$ & $94.1(1.8)$ & $90.1(0.1)$ & $107.9(2.7)$ \\
\hline 48 & Cyprodinil & 5 & 7 & $93.9(0.7)$ & $94.7(2.2)$ & $83.3(3.3)$ & $100.8(0.6)$ \\
\hline 49 & Cyromazine & 0.01 & 0.05 & $40.3(5.2)$ & $44.3(1.7)$ & $39.3(7.0)$ & $39.3(5.9)$ \\
\hline 50 & DDVP (Dichlovos) & 1 & 5 & $98.2(1.0)$ & $92.6(4.4$ & $108.7(12.8)$ & $112.0(5.2)$ \\
\hline 51 & Dinotefuran & 0.1 & 0.5 & $106.7(4.2)$ & $99.6(1.9)$ & $84.5(1.8)$ & $97.1(1.0)$ \\
\hline 52 & Diafenthiuron & 0.01 & 0.05 & - & 5.87 & $14.0(20.6)$ & $37.1(5.4)$ \\
\hline 53 & Diazinon & 0.05 & 0.1 & $101.2(2.4)$ & $96.4(1.1)$ & $98.9(3.7)$ & $102.9(2.0)$ \\
\hline 54 & Dichlofluanid ${ }^{*}$ & 0.1 & 0.5 & $108.6(2.1)$ & $115.6(2.3)$ & - & - \\
\hline 55 & Diethofencarb & 0.2 & 0.5 & $89.5(13.2)$ & $92.0(8.5)$ & $77.9(1.1)$ & $93.2(2.4)$ \\
\hline 56 & Difenoconazole & 0.5 & 1 & $103.7(1.7)$ & $100.8(1.7)$ & $87.2(6.1)$ & $106.7(1.6)$ \\
\hline 57 & Diflubenzuron & 0.5 & 1 & $102.9(2.5)$ & $98.2(0.9)$ & $93.2(0.6)$ & $97.6(1.8)$ \\
\hline 58 & Dimepiperate & 1 & 5 & $99.7(1.2)$ & $96.5(1.1)$ & $86.8(2.9)$ & $102.9(1.9)$ \\
\hline 59 & Dimethametryn & 0.01 & 0.05 & $99.7(2.0)$ & $97.3(1.0)$ & $94.1(4.2)$ & $102.1(3.8)$ \\
\hline 60 & Dimethenamid & 0.05 & 0.5 & $100.6(4.1)$ & $96.4(0.3)$ & $90.2(3.0)$ & $108.0(2.1)$ \\
\hline 61 & Dimethoate $^{*}$ & 0.01 & 0.05 & $104.8(1.8)$ & $102.5(0.7)$ & $84.6(1.1)$ & $106.6(0.8)$ \\
\hline 62 & Dimethomorph & 0.5 & 1 & $91.4(4.2)$ & $94.6(1.4)$ & $96.1(2.8)$ & $101.5(1.3)$ \\
\hline 63 & Dimethylvinphos* & 0.5 & 1 & $78.2(6.7)$ & $93.3(0.2)$ & $103.6(6.6)$ & $114.2(3.9)$ \\
\hline 64 & Demeton-S-Methyl & 0.01 & 0.05 & $101.1(5.1)$ & $93.4(2.0)$ & $90.1(3.8)$ & $103.7(1.4)$ \\
\hline 65 & Diniconazole & 0.5 & 1 & $100.2(2.6)$ & $97.5(3.4)$ & $97.5(1.2)$ & $103.3(2.9)$ \\
\hline 66 & Diphenamid & 0.05 & 0.1 & $100.1(4.2)$ & $95.6(1.6)$ & $86.1(3.2)$ & $102.3(2.2)$ \\
\hline 67 & Dithiopyr & 1 & 2 & $94.1(4.0)$ & $98.1(2.3)$ & $81.0(15.0)$ & $98.4(2.2)$ \\
\hline 68 & Diuron & 0.05 & 0.5 & $102.3(2.8)$ & $96.6(1.3)$ & $83.3(2.5)$ & $104.1(1.3)$ \\
\hline 69 & Dymron & 0.01 & 0.05 & $107.3(2.6)$ & $98.3(2.0)$ & $89.5(5.9)$ & $110.2(2.9)$ \\
\hline 70 & Edifenphos & 0.1 & 0.5 & $105.7(2.8)$ & $100.8(0.8)$ & $90.2(4.1)$ & $112.5(1.2)$ \\
\hline 71 & $\mathrm{EPN}^{*}$ & 0.7 & 1 & $95.9(14.9)$ & $99.4(7.1)$ & $75.2(3.5)$ & $103.9(7.6)$ \\
\hline 72 & Esprocarb & 0.05 & 0.1 & $97.3(1.9)$ & $92.3(0.4)$ & $84.7(3.0)$ & $102.8(1.1)$ \\
\hline 73 & Ethaboxam & 0.5 & 1 & $104.1(1.0)$ & $96.9(1.0)$ & $86.9(9.7)$ & $99.9(1.2)$ \\
\hline 74 & Ethiofencarb & 0.05 & 0.3 & $95.8(3.2)$ & $92.6(1.7)$ & $87.2(1.2)$ & $104.2(2.1)$ \\
\hline 75 & Ethofenprox & 0.1 & 0.5 & $96.7(0.7)$ & $97.9(7.5)$ & $81.6(1.0)$ & $101.1(0.4)$ \\
\hline 76 & Ethoprophos & 0.1 & 0.5 & $100.6(4.2)$ & $92.6(1.6)$ & $87.0(0.6)$ & $99.9(1.8)$ \\
\hline 77 & Ethoxyquin & 0.3 & 0.5 & $33.4(3.2)$ & $34.3(2.1)$ & $65.9(2.2)$ & $86.4(4.0)$ \\
\hline 78 & Ethoxysulfuron & 0.005 & 0.01 & $101.1(7.8)$ & $86.1(1.5)$ & $82.8(2.8)$ & $93.5(9.7)$ \\
\hline 79 & Etoxazole & 0.01 & 0.05 & $110.0(10.2)$ & $102.6(4.3)$ & $85.6(1.1)$ & $95.5(2.7)$ \\
\hline 80 & Etrimfos & 0.1 & 0.5 & $99.1(1.6)$ & $95.9(1.4)$ & $99.4(3.6)$ & $104.2(2.8)$ \\
\hline 81 & Famoxadone & 0.3 & 0.5 & $96.3(1.7)$ & $95.8(3.5)$ & $102.3(9.7)$ & $101.7(1.9)$ \\
\hline 82 & Fenamidone $^{*}$ & 0.05 & 0.2 & $100.0(4.3)$ & $97.3(1.3)$ & $86.4(6.3)$ & $98.0(3.4)$ \\
\hline 83 & Fenamiphos $^{*}$ & 0.05 & 0.1 & $102.5(3.6)$ & $96.4(1.0)$ & $81.0(2.8)$ & $106.8(1.0)$ \\
\hline 84 & Fenarimol & 4 & 5 & $103.6(8.4)$ & $95.6(3.6)$ & $86.5(9.3)$ & $101.7(4.9)$ \\
\hline 85 & Fenazaquin & 0.1 & 0.5 & $95.7(18.7)$ & $96.7(4.4)$ & $85.6(2.2)$ & $95.5(1.5)$ \\
\hline 86 & Fenbuconazole & 0.5 & 1 & $103.5(1.4)$ & $94.3(3.0)$ & $93.4(2.9)$ & $101.4(1.1)$ \\
\hline 87 & Fenhexamid & 0.1 & 0.3 & - & - & $82.9(9.6)$ & $103.5(4.6)$ \\
\hline 88 & Fenobucarb (BPMC) & 0.1 & 1 & $88.7(8.0)$ & $87.8(6.3)$ & $78.5(5.4)$ & $91.4(4.0)$ \\
\hline
\end{tabular}


Table 5. Continued

\begin{tabular}{|c|c|c|c|c|c|c|c|}
\hline \multirow[t]{2}{*}{ No. } & \multirow[t]{2}{*}{ Compound } & \multirow{2}{*}{$\begin{array}{l}\text { LOD } \\
(\mu \mathrm{g} / \mathrm{kg})\end{array}$} & \multirow{2}{*}{$\begin{array}{c}\text { LOQ } \\
(\mu \mathrm{g} / \mathrm{kg})\end{array}$} & \multicolumn{2}{|c|}{$\begin{array}{c}\text { Recovery, \% (RSD, \%) } \\
\text { Apple }\end{array}$} & \multicolumn{2}{|c|}{$\begin{array}{c}\text { Recovery, \% (RSD, \%) } \\
\text { Rice }\end{array}$} \\
\hline & & & & $50 \mu \mathrm{g} / \mathrm{kg}$ & $200 \mu \mathrm{g} / \mathrm{kg}$ & $50 \mu \mathrm{g} / \mathrm{kg}$ & $200 \mu \mathrm{g} / \mathrm{kg}$ \\
\hline 89 & Fenothiocarb* & 0.01 & 0.05 & $105.3(0.3)$ & $96.1(2.1)$ & $79.1(0.8)$ & $106.6(2.6)$ \\
\hline 90 & Fenoxanil & 1 & 5 & $108.4(2.9)$ & $95.7(0.6)$ & 83.1(3.3) & $102.5(3.0)$ \\
\hline 91 & Fenoxaprop-Ethyl & 0.03 & 0.05 & $103.7(4.5)$ & $96.8(2.0)$ & $83.7(2.4)$ & $105.4(1.6)$ \\
\hline 92 & Fenoxycarb & 0.03 & 0.05 & $103.8(3.1)$ & $97.5(0.7)$ & $88.0(5.2)$ & $105.4(1.1)$ \\
\hline 93 & Fenpyroximate & 0.7 & 1 & $97.5(2.7)$ & $91.6(4.4)$ & $91.6(2.1)$ & $99.6(1.4)$ \\
\hline 94 & Fenthion(MPP) & 0.1 & 0.5 & $97.6(3.5)$ & $91.4(2.0)$ & $86.3(8.7)$ & $103.1(4.6)$ \\
\hline 95 & Fentrazamide & 0.03 & 0.05 & $99.0(4.2)$ & $96.4(2.4)$ & $103.3(2.6)$ & $105.4(3.8)$ \\
\hline 96 & Ferimzone $^{*}$ & 0.05 & 0.1 & $93.1(3.7)$ & $89.4(3.2)$ & $75.3(0.3)$ & $87.2(1.3)$ \\
\hline 97 & Flonicamid & 0.1 & 0.5 & $103.2(3.7)$ & $93.5(0.5)$ & $93.8(3.5)$ & $100.7(1.3)$ \\
\hline 98 & Fluacrypyrim & 0.05 & 0.1 & $101.9(0.3)$ & $96.0(1.5)$ & $84.2(3.9)$ & $101.3(0.8)$ \\
\hline 99 & Flubendiamide & 0.5 & 1 & $104.9(2.9)$ & $95.6(0.3)$ & $94.3(3.9)$ & $100.5(1.3)$ \\
\hline 100 & Flucetosulfuron & 0.04 & 0.05 & $107.3(2.4)$ & $100.8(2.4)$ & $102.3(5.6)$ & $117.6(2.2)$ \\
\hline 101 & Fludioxonil $^{*}$ & 0.5 & 1 & $104.9(7.9)$ & $96.4(0.9)$ & $106.4(1.5)$ & $110.5(1.2)$ \\
\hline 102 & Flufenacet & 0.1 & 0.5 & $103.8(3.7)$ & $95.8(1.4)$ & $86.9(4.0)$ & $107.8(1.7)$ \\
\hline 103 & Flufenoxuron & 0.05 & 0.1 & $96.8(0.5)$ & $89.8(10.6)$ & $87.1(2.5)$ & $97.6(0.1)$ \\
\hline 104 & Flumioxazin & 4 & 5 & $98.5(8.4)$ & $95.7(6.6)$ & $76.7(7.3)$ & $105.5(3.4)$ \\
\hline 105 & Fluopicolide & 0.05 & 0.1 & 108.9(3.2) & $94.1(1.4)$ & $84.7(8.0)$ & $111.8(1.9)$ \\
\hline 106 & Fluopyram* $^{*}$ & 0.01 & 0.05 & $112.8(1.0)$ & $96.6(0.9)$ & $82.3(6.7)$ & $110.0(2.1)$ \\
\hline 107 & Fluquinconazole & 0.05 & 0.1 & $99.3(5.8)$ & $94.5(2.9)$ & $86.2(7.4)$ & $107.1(3.5)$ \\
\hline 108 & Flusilazole & 0.5 & 1 & $107.7(0.9)$ & $95.1(1.5)$ & $82.8(0.3)$ & $109.7(3.5)$ \\
\hline 109 & Flutolanil & 0.01 & 0.05 & $102.5(4.8)$ & $94.3(4.1)$ & $79.7(0.4)$ & $108.9(3.7)$ \\
\hline 110 & Forchlorfenuron & 0.1 & 0.5 & $98.6(2.4)$ & $92.6(1.1)$ & $84.2(2.4)$ & $97.5(2.4)$ \\
\hline 111 & Fosthiazate & 0.01 & 0.05 & 104.6(1.7) & $95.7(1.0)$ & $90.1(1.9)$ & $102.7(1.6)$ \\
\hline 112 & Furathiocarb & 0.05 & 0.1 & $101.7(1.4)$ & $95.6(0.2)$ & $84.7(3.7)$ & $100.4(0.7)$ \\
\hline 113 & Gibberellic acid & 10 & 15 & $110.6(10.5)$ & $100.9(6.6)$ & $81.1(7.0)$ & $88.4(3.9)$ \\
\hline 114 & Halosulfuron-methyl & 0.05 & 0.1 & $99.9(5.4)$ & 89.2(1.9) & $86.9(1.6)$ & $93.9(8.0)$ \\
\hline 115 & Haloxyfop & 0.3 & 0.5 & $105.6(1.1)$ & $91.6(1.0)$ & $84.5(12.7)$ & $96.6(2.8)$ \\
\hline 116 & Hexaconazole & 0.1 & 0.5 & $100.6(1.8)$ & $92.5(0.8)$ & $88.4(5.6)$ & $100.0(0.7)$ \\
\hline 117 & Hexaflumuron & 5 & 10 & $89.0(14.7)$ & $93.7(4.0)$ & 100.1(11.6) & $96.2(1.6)$ \\
\hline 118 & Hexazinone & 0.005 & 0.01 & $105.0(1.8)$ & $96.0(1.0)$ & $86.2(4.3)$ & $103.0(2.6)$ \\
\hline 119 & Hexythiazox & 0.05 & 0.1 & $100.3(1.6)$ & $92.6(3.3)$ & $86.6(1.7)$ & $96.5(1.6)$ \\
\hline 120 & Imazalil $^{*}$ & 0.05 & 0.1 & $99.9(0.8)$ & $94.2(1.1)$ & $88.1(1.5)$ & $100.1(3.1)$ \\
\hline 121 & Imazosulfuron & 0.08 & 0.1 & $107.2(3.1)$ & $101.1(3.0)$ & $97.4(9.5)$ & $114.9(1.1)$ \\
\hline 122 & Imibenconazole & 0.7 & 1 & $98.1(11.4)$ & $102.1(6.1)$ & $110.3(5.0)$ & $109.9(0.5)$ \\
\hline 123 & Imicyafos & 0.008 & 0.01 & $110.9(3.2)$ & $101.6(0.8)$ & $90.4(3.3)$ & $103.0(2.1)$ \\
\hline 124 & Imidacloprid & 0.5 & 1 & $77.5(5.4)$ & $81.8(1.6)$ & $91.2(1.7)$ & $100.9(0.7)$ \\
\hline 125 & Inabenfide & 0.8 & 1 & $96.8(2.2)$ & $92.4(2.9)$ & $103.6(2.2)$ & $97.7(5.3)$ \\
\hline 126 & Iprobenfos & 0.01 & 0.05 & $100.4(1.2)$ & $93.8(0.8)$ & $88.6(1.2)$ & $100.3(0.9)$ \\
\hline 127 & Iprovalicarb & 0.05 & 0.1 & $95.5(3.3)$ & $93.9(1.0)$ & $91.4(4.4)$ & $101.5(1.4)$ \\
\hline 128 & Isoprocarb (MIPC) & 0.1 & 1 & $100.6(1.0)$ & $91.8(0.9)$ & $87.0(4.0)$ & $100.9(2.7)$ \\
\hline 129 & Isoprothiolane & 0.05 & 0.1 & $103.4(0.9)$ & $94.9(1.6)$ & $77.0(2.8)$ & $105.5(3.2)$ \\
\hline 130 & Isopyrazam & 0.03 & 0.05 & $105.8(1.1)$ & $96.6(0.7)$ & $83.1(6.6)$ & $106.1(1.6)$ \\
\hline 131 & Kresoxim-methyl & 0.5 & 1 & 101.8(3.9) & $96.0(1.8)$ & $99.3(5.5)$ & $105.1(1.4)$ \\
\hline 132 & Linuron & 0.01 & 0.05 & $82.9(14.3)$ & $87.6(12.2)$ & $76.5(2.4)$ & $91.7(6.5)$ \\
\hline
\end{tabular}


Table 5. Continued

\begin{tabular}{|c|c|c|c|c|c|c|c|}
\hline \multirow[t]{2}{*}{ No. } & \multirow[t]{2}{*}{ Compound } & \multirow{2}{*}{$\begin{array}{c}\text { LOD } \\
(\mu \mathrm{g} / \mathrm{kg})\end{array}$} & \multirow{2}{*}{$\begin{array}{c}\text { LOQ } \\
(\mu \mathrm{g} / \mathrm{kg})\end{array}$} & \multicolumn{2}{|c|}{$\begin{array}{c}\text { Recovery, \% (RSD, \%) } \\
\text { Apple }\end{array}$} & \multicolumn{2}{|c|}{$\begin{array}{c}\text { Recovery, \% (RSD, \%) } \\
\text { Rice }\end{array}$} \\
\hline & & & & $50 \mu \mathrm{g} / \mathrm{kg}$ & $200 \mu \mathrm{g} / \mathrm{kg}$ & $50 \mu \mathrm{g} / \mathrm{kg}$ & $200 \mu \mathrm{g} / \mathrm{kg}$ \\
\hline 133 & Lufenuron $^{*}$ & 0.1 & 0.5 & $93.7(16.8)$ & $91.7(9.9)$ & $84.8(10.5)$ & $95.7(1.9)$ \\
\hline 134 & Malathion & 0.5 & 1 & $106.3(3.1)$ & $94.5(2.3)$ & $80.3(6.5)$ & $110.0(0.8)$ \\
\hline 135 & Mandipropamid & 0.05 & 0.1 & $100.9(0.4)$ & $94.0(1.5)$ & $73.0(0.9)$ & $100.3(1.1)$ \\
\hline 136 & Mefenacet & 0.05 & 0.1 & $102.5(1.6)$ & $95.3(1.3)$ & $87.9(2.9)$ & $102.0(1.7)$ \\
\hline 137 & Mepanipyrim & 1 & 2 & $101.2(2.3)$ & $94.2(1.2)$ & $80.3(9.7)$ & $101.8(3.0)$ \\
\hline 138 & Mepronil & 0.05 & 0.08 & $108.8(1.8)$ & $92.5(1.3)$ & $78.5(6.4)$ & $111.2(2.9)$ \\
\hline 139 & Metalaxyl & 0.05 & 0.1 & $104.0(2.0)$ & $94.7(0.9)$ & $88.4(1.1)$ & $101.5(0.8)$ \\
\hline 140 & Metamifop & 0.05 & 0.1 & $102.3(4.4)$ & $98.6(2.3)$ & $88.3(2.6)$ & $106.2(0.1)$ \\
\hline 141 & Metazosulfuron & 0.08 & 0.1 & $109.4(8.1)$ & $113.8(2.2)$ & $92.5(1.2)$ & $89.1(4.5)$ \\
\hline 142 & Metconazole & 0.1 & 0.5 & $103.8(1.0)$ & $94.4(0.6)$ & $88.8(4.1)$ & $101.4(2.4)$ \\
\hline 143 & Methabenzthiazuron & 0.05 & 0.1 & $98.9(2.2)$ & $92.4(0.2)$ & $83.5(5.6)$ & $99.5(1.6)$ \\
\hline 144 & Methidathion* & 0.1 & 0.5 & $103.5(1.2)$ & $95.4(2.2)$ & $83.6(2.4)$ & $102.9(1.5)$ \\
\hline 145 & Methiocarb & 0.1 & 0.5 & $99.3(2.4)$ & $92.2(0.7)$ & $87.9(1.5)$ & $104.7(1.8)$ \\
\hline 146 & Methomyl & 0.05 & 0.1 & $100.6(2.0)$ & $91.9(0.2)$ & $106.6(3.7)$ & $114.7(0.6)$ \\
\hline 147 & Methoxyfenozide & 0.1 & 0.5 & 109.9(1.6) & $95.0(0.1)$ & $86.6(1.9)$ & $112.9(0.9)$ \\
\hline 148 & Metobromuron $^{*}$ & 0.1 & 0.5 & $98.5(3.2)$ & $93.5(0.9)$ & $90.3(5.5)$ & $98.7(1.6)$ \\
\hline 149 & Metolachlor ${ }^{*}$ & 1 & 2 & $100.5(2.1)$ & $92.0(0.7)$ & $86.9(1.2)$ & $100.4(2.4)$ \\
\hline 150 & Metolcarb & 0.1 & 1 & $104.1(1.2)$ & $94.9(1.2)$ & $88.4(2.5)$ & $101.2(5.1)$ \\
\hline 151 & Metrafenone & 0.03 & 0.05 & $100.6(0.9)$ & $97.7(0.5)$ & $90.9(2.0)$ & $100.2(0.6)$ \\
\hline 152 & Metribuzin" & 1 & 5 & $110.9(0.8)$ & $97.1(2.9)$ & $76.0(3.7)$ & $115.2(3.4)$ \\
\hline 153 & Mevinphos $(E, Z)^{*}$ & 0.1 & 0.5 & $106.7(1.5)$ & $95.4(0.5)$ & $84.8(2.8)$ & $97.9(1.1)$ \\
\hline \multirow{2}{*}{154} & Milbemectin A3 & 0.3 & 0.5 & $95.4(3.2)$ & $93.4(4.3)$ & $86.4(5.9)$ & $98.0(3.3)$ \\
\hline & Milbemectin A4 & 0.5 & 1 & $92.2(4.0)$ & $96.2(2.0)$ & $79.3(3.6)$ & $95.7(2.2)$ \\
\hline 155 & Molinate & 5 & 10 & $101.7(0.5)$ & $95.9(8.9)$ & $85.4(5.1)$ & $95.0(6.4)$ \\
\hline 156 & Monocrotophos & 0.1 & 0.5 & 103.6(1.6) & $97.4(0.4)$ & $85.8(1.3)$ & 101.1(1.9) \\
\hline 157 & Myclobutanil & 1 & 2 & 103.7(1.8) & $93.2(0.9)$ & $89.2(6.8)$ & $109.2(1.8)$ \\
\hline 158 & Napropamide & 0.05 & 0.1 & $103.0(1.0)$ & $95.0(1.4)$ & $90.1(4.9)$ & $103.3(1.8)$ \\
\hline 159 & Nicosulfuron & 0.005 & 0.01 & $84.4(1.7)$ & $82.4(1.6)$ & $83.7(2.4)$ & $91.5(2.8)$ \\
\hline 160 & Novaluron ${ }^{*}$ & 0.5 & 1 & $84.7(13.1)$ & $91.4(4.8)$ & $92.9(5.6)$ & $98.4(2.9)$ \\
\hline 161 & Nuarimol & 2 & 5 & $325.3(0.4)$ & $159.8(1.0)$ & $502.4(4.2)$ & $183.0(3.6)$ \\
\hline 162 & Ofurace & 0.05 & 0.5 & $108.5(3.1)$ & $93.8(1.7)$ & $83.4(5.4)$ & $107.6(1.9)$ \\
\hline 163 & Omethoate & 0.1 & 0.5 & $91.1(2.8)$ & $90.8(1.6)$ & $87.8(1.4)$ & $95.9(1.2)$ \\
\hline 164 & Oxadiazon & 0.1 & 0.5 & $95.8(3.9)$ & $92.1(2.9)$ & $92.0(2.0)$ & $93.8(1.1)$ \\
\hline 165 & Oxadixyl & 0.008 & 0.01 & 109.3(2.6) & $99.8(0.2)$ & $81.0(3.9)$ & $104.3(2.6)$ \\
\hline 166 & Oxamyl & 0.01 & 0.05 & $102.3(1.5)$ & $94.1(0.3)$ & $92.7(1.1)$ & $100.3(1.1)$ \\
\hline 167 & Oxaziclomefon & 0.05 & 0.1 & 99.3(7.6) & $95.7(1.6)$ & $88.5(3.1)$ & $101.6(0.6)$ \\
\hline 168 & Paclobutrazol & 0.5 & 1 & $101.3(5.1)$ & $93.7(0.5)$ & $95.9(7.3)$ & $110.0(2.7)$ \\
\hline 169 & Penconazole & 0.1 & 0.5 & $100.2(0.7)$ & $93.9(1.1)$ & 88.1(3.6) & $103.2(2.7)$ \\
\hline 170 & Pencycuron & 0.05 & 0.1 & $96.8(3.3)$ & $94.5(1.8)$ & $106.7(3.8)$ & $109.2(2.6)$ \\
\hline 171 & Pendimethalin ${ }^{*}$ & 1 & 2 & $89.3(3.8)$ & $89.9(4.8)$ & $100.7(7.0)$ & $96.0(2.9)$ \\
\hline 172 & Penoxsulam & 0.03 & 0.05 & $101.2(3.3)$ & $93.4(1.7)$ & $100.7(5.2)$ & $102.3(2.7)$ \\
\hline 173 & Penthiopyrad* & 0.008 & 0.01 & $104.5(2.0)$ & $94.7(0.8)$ & $85.8(2.6)$ & $110.1(0.8)$ \\
\hline 174 & Pentoxazone & 1 & 5 & $102.6(6.6)$ & $99.6(5.1)$ & $98.8(12.5)$ & $109.8(6.3)$ \\
\hline 175 & Phenthoate & 0.1 & 0.5 & $95.8(2.1)$ & $93.9(1.8)$ & $89.2(3.3)$ & $100.4(3.4)$ \\
\hline
\end{tabular}


Table 5. Continued

\begin{tabular}{|c|c|c|c|c|c|c|c|}
\hline \multirow[t]{2}{*}{ No. } & \multirow[t]{2}{*}{ Compound } & \multirow{2}{*}{$\begin{array}{l}\text { LOD } \\
(\mu \mathrm{g} / \mathrm{kg})\end{array}$} & \multirow{2}{*}{$\begin{array}{c}\text { LOQ } \\
(\mu \mathrm{g} / \mathrm{kg})\end{array}$} & \multicolumn{2}{|c|}{$\begin{array}{c}\text { Recovery, \% (RSD, \%) } \\
\text { Apple }\end{array}$} & \multicolumn{2}{|c|}{$\begin{array}{c}\text { Recovery, \% (RSD, \%) } \\
\text { Rice }\end{array}$} \\
\hline & & & & $50 \mu \mathrm{g} / \mathrm{kg}$ & $200 \mu \mathrm{g} / \mathrm{kg}$ & $50 \mu \mathrm{g} / \mathrm{kg}$ & $200 \mu \mathrm{g} / \mathrm{kg}$ \\
\hline 176 & Phorate & 0.05 & 1 & $96.6(5.9)$ & $91.8(4.0)$ & $95.1(6.3)$ & $108.2(4.6)$ \\
\hline 177 & Phosalone & 0.1 & 0.5 & $99.3(1.1)$ & $95.7(0.7)$ & $81.2(2.4)$ & $106.7(0.1)$ \\
\hline 178 & Phosphamidone & 0.05 & 0.1 & $105.2(1.4)$ & $97.0(0.7)$ & $94.4(1.7)$ & $100.8(2.3)$ \\
\hline 179 & Phoxim & 0.03 & 0.05 & $95.2(1.6)$ & $93.7(1.4)$ & $91.7(1.8)$ & $102.1(0.9)$ \\
\hline 180 & Picoxystrobin ${ }^{*}$ & 0.01 & 0.05 & $100.7(1.8)$ & $94.9(1.3)$ & $94.8(2.2)$ & $89.6(0.9)$ \\
\hline 181 & Piperophos & 0.05 & 0.1 & $99.8(0.2)$ & $92.2(1.0)$ & $85.6(1.7)$ & $99.8(1.7)$ \\
\hline 182 & Pirimicarb & 0.01 & 0.05 & $100.2(1.4)$ & $93.4(0.5)$ & $90.6(1.9)$ & $102.4(2.7)$ \\
\hline 183 & Pirimiphos-methyl & 0.1 & 0.5 & 99.3(1.9) & $94.2(1.4)$ & $92.8(3.1)$ & $102.2(1.4)$ \\
\hline 184 & Probenazole ${ }^{*}$ & 5 & 15 & $100.6(2.5)$ & $94.2(1.1)$ & $81.0(6.7)$ & $100.9(3.1)$ \\
\hline 185 & Prochloraz & 0.5 & 1 & $95.8(0.3)$ & $92.8(0.7)$ & $93.6(5.2)$ & $99.6(1.9)$ \\
\hline 186 & Profenofos & 0.1 & 0.5 & $101.1(1.5)$ & $95.1(0.8)$ & $86.3(1.5)$ & $101.6(1.8)$ \\
\hline 187 & Prometryn ${ }^{*}$ & 0.1 & 0.5 & $97.1(1.8)$ & $90.7(0.6)$ & $89.2(2.6)$ & $102.2(0.9)$ \\
\hline 188 & Propamocarb & 0.005 & 0.01 & $86.1(6.4)$ & $85.6(1.5)$ & $82.2(2.5)$ & $92.2(1.1)$ \\
\hline 189 & Propanil & 1 & 5 & $94.5(3.4)$ & $91.8(1.4)$ & $89.3(4.0)$ & $104.8(2.5)$ \\
\hline 190 & Propaquizafop & 0.03 & 0.05 & $99.2(2.2)$ & $97.6(1.2)$ & $87.6(2.9)$ & $81.5(1.4)$ \\
\hline 191 & Propiconazole ${ }^{*}$ & 0.7 & 1 & $97.1(0.4)$ & $91.8(1.0)$ & $93.9(1.4)$ & $106.4(1.1)$ \\
\hline 192 & Propoxur & 0.05 & 0.1 & $105.3(2.5)$ & $92.6(1.3)$ & $87.5(3.1)$ & $104.9(1.4)$ \\
\hline 193 & Pymetrozine & 0.03 & 0.05 & $53.0(0.6)$ & $52.8(1.1)$ & $62.8(0.7)$ & $73.5(3.0)$ \\
\hline 194 & Pyraclofos & 0.5 & 1 & $96.2(2.2)$ & $91.8(0.5)$ & $94.6(0.9)$ & $97.6(2.5)$ \\
\hline 195 & Pyraclostrobin & 0.05 & 0.2 & $97.7(1.5)$ & $95.0(0.8)$ & $93.8(1.9)$ & $102.7(1.9)$ \\
\hline 196 & Pyrazolate & 0.05 & 0.1 & $101.6(1.1)$ & $97.3(0.2)$ & $81.4(3.7)$ & $105.2(0.4)$ \\
\hline 197 & Pyrazophos & 0.1 & 0.5 & $96.3(1.9)$ & $94.1(0.3)$ & $99.8(3.2)$ & $98.2(0.8)$ \\
\hline 198 & Pyribenzoxim & 1 & 2 & $98.0(2.3)$ & $94.7(2.0)$ & $86.1(4.7)$ & $104.0(1.8)$ \\
\hline 199 & Pyributicarb & 0.05 & 0.1 & $93.7(12.1)$ & $94.5(1.9)$ & $88.9(0.8)$ & $101.8(0.1)$ \\
\hline 200 & Pyridaben & 0.05 & 0.1 & $97.9(3.0)$ & $92.5(9.3)$ & $57.4(1.2)$ & $72.2(2.1)$ \\
\hline 201 & Pyridaphenthion* & 0.1 & 0.5 & $102.4(1.1)$ & $95.1(1.3)$ & $90.0(4.6)$ & $103.5(2.1)$ \\
\hline 202 & Pyrifluquinazon & 0.005 & 0.01 & $95.6(2.4)$ & $97.6(1.4)$ & $87.0(1.1)$ & $107.1(4.2)$ \\
\hline 203 & Pyriftalid & 0.5 & 1 & $103.2(4.2)$ & $96.4(0.9)$ & $88.4(3.3)$ & $105.4(2.7)$ \\
\hline 204 & Pyrimethanil & 1 & 5 & $97.6(5.6)$ & $97.1(1.4)$ & $109.7(9.3)$ & $95.9(4.8)$ \\
\hline 205 & Pyrimidifen & 0.05 & 0.1 & $100.3(1.4)$ & $96.9(0.2)$ & $98.6(4.9)$ & $104.7(0.9)$ \\
\hline \multirow{2}{*}{206} & Pyriminobac-methyl $(Z)$ & 0.1 & 0.5 & $100.3(2.5)$ & $93.2(0.7)$ & $87.9(1.7)$ & $101.9(1.2)$ \\
\hline & Pyriminobac-methyl $(E)$ & 0.1 & 0.5 & $99.9(2.3)$ & $92.7(0.6)$ & $90.9(4.1)$ & $102.0(2.8)$ \\
\hline 207 & Pyrimisulfan & 0.008 & 0.01 & $99.5(1.7)$ & $93.5(1.0)$ & $96.9(1.7)$ & $100.6(1.5)$ \\
\hline 208 & Pyriproxyfen & 0.05 & 0.1 & $92.3(15.1)$ & $94.4(3.5)$ & $93.7(2.3)$ & $102.9(0.7)$ \\
\hline 209 & Pyroquilon & 0.05 & 0.1 & $97.6(1.2)$ & $92.0(0.4)$ & $81.3(3.4)$ & $103.9(2.6)$ \\
\hline 210 & Quinalphos & 0.03 & 0.05 & $100.5(0.3)$ & $94.4(0.5)$ & $92.5(4.2)$ & $103.9(0.4)$ \\
\hline 211 & Quinmerac & 0.005 & 0.01 & $105.6(7.6)$ & $94.7(0.8)$ & $71.5(0.5)$ & $88.7(2.2)$ \\
\hline 212 & Quinoclamine $^{*}$ & 1 & 5 & $95.0(6.1)$ & $94.9(2.4)$ & $88.2(7.4)$ & $103.4(5.0)$ \\
\hline 213 & Quizalofop-ethyl & 0.01 & 0.05 & $100.4(2.8)$ & $95.2(1.5)$ & $88.8(2.5)$ & $106.9(1.6)$ \\
\hline 214 & Saflufenacil & 0.03 & 0.05 & $99.7(6.6)$ & $94.4(3.1)$ & $99.7(6.6)$ & $100.2(5.6)$ \\
\hline 215 & Sethoxydim & 0.03 & 0.05 & $91.4(1.1)$ & $93.4(0.5)$ & $95.6(2.9)$ & $95.3(1.3)$ \\
\hline 216 & Silafluofen* & 0.03 & 0.05 & $91.6(1.3)$ & $97.9(0.3)$ & $99.4(0.6)$ & $101.3(0.6)$ \\
\hline 217 & Simeconazole $^{*}$ & 1 & 3 & $98.5(6.4)$ & $93.1(1.3)$ & $86.6(7.2)$ & $107.6(4.9)$ \\
\hline 218 & Simetryn* & 0.05 & 0.1 & $98.1(1.7)$ & $91.0(0.2)$ & $90.8(3.0)$ & $101.3(1.0)$ \\
\hline
\end{tabular}


Table 5. Continued

\begin{tabular}{|c|c|c|c|c|c|c|c|}
\hline \multirow[t]{2}{*}{ No. } & \multirow[t]{2}{*}{ Compound } & \multirow{2}{*}{$\begin{array}{c}\text { LOD } \\
(\mu \mathrm{g} / \mathrm{kg})\end{array}$} & \multirow{2}{*}{$\begin{array}{c}\text { LOQ } \\
(\mu \mathrm{g} / \mathrm{kg})\end{array}$} & \multicolumn{2}{|c|}{$\begin{array}{c}\text { Recovery, \% (RSD, \%) } \\
\text { Apple }\end{array}$} & \multicolumn{2}{|c|}{$\begin{array}{c}\text { Recovery, \% (RSD, \%) } \\
\text { Rice }\end{array}$} \\
\hline & & & & $50 \mu \mathrm{g} / \mathrm{kg}$ & $200 \mu \mathrm{g} / \mathrm{kg}$ & $50 \mu \mathrm{g} / \mathrm{kg}$ & $200 \mu \mathrm{g} / \mathrm{kg}$ \\
\hline \multirow{2}{*}{219} & Spinetoram (j) & 0.03 & 0.05 & $91.6(2.5)$ & $90.3(0.8)$ & $100.3(0.3)$ & $101.1(3.1)$ \\
\hline & Spinetoram (L) & 0.03 & 0.05 & $91.0(1.0)$ & $91.6(2.3)$ & 101.1(1.2) & $98.4(4.9)$ \\
\hline 220 & Spirodiclofen & 0.05 & 0.1 & $94.9(9.3)$ & $93.1(6.9)$ & $83.3(2.8)$ & $100.6(1.9)$ \\
\hline 221 & Spiromesifen ${ }^{*}$ & 0.7 & 1 & $97.8(14.1)$ & $91.0(6.2)$ & $92.3(4.2)$ & $98.4(0.5)$ \\
\hline 222 & Sulfoxaflor & 0.005 & 0.01 & $81.3(0.7)$ & $88.6(1.8)$ & $81.0(3.6)$ & $90.3(1.6)$ \\
\hline 223 & Tebuconazole & 0.1 & 0.5 & $101.3(2.2)$ & $94.4(1.0)$ & $92.6(3.6)$ & $101.2(1.7)$ \\
\hline 224 & Tebufenozide & 0.1 & 0.5 & $101.5(2.5)$ & $95.6(2.2)$ & $92.9(6.4)$ & $108.7(1.7)$ \\
\hline 225 & Tebufenpyrad & 0.1 & 0.5 & $97.0(12.4)$ & $101.8(5.4)$ & $90.1(3.1)$ & $86.3(1.9)$ \\
\hline 226 & Tebupirimfos* & 0.05 & 0.1 & $93.2(3.9)$ & $92.5(0.7)$ & $104.7(2.5)$ & $102.4(0.9)$ \\
\hline 227 & Teflubenzuron & 4 & 5 & $91.7(6.6)$ & $99.5(2.9)$ & $86.7(6.8)$ & $98.3(2.2)$ \\
\hline 228 & Terbuthylazine & 0.5 & 1 & $105.4(0.7)$ & $94.4(1.1)$ & $89.2(2.5)$ & $112.4(2.4)$ \\
\hline 229 & Terbutryn* & 0.05 & 0.1 & $97.7(0.5)$ & $92.6(0.3)$ & $89.6(2.9)$ & $101.7(2.5)$ \\
\hline 230 & Tetraconazole & 0.1 & 1 & $97.8(5.1)$ & $93.9(1.7)$ & $113.0(4.1)$ & $112.3(2.3)$ \\
\hline 231 & Thenylchlor & 0.03 & 0.05 & $104.5(2.8)$ & $94.5(1.3)$ & $90.9(1.4)$ & $103.8(1.9)$ \\
\hline 232 & Thiabendazole & 0.5 & 1 & $95.3(1.8)$ & $92.9(1.2)$ & $86.1(3.3)$ & $93.3(0.9)$ \\
\hline 233 & Thiacloprid & 0.03 & 0.05 & $100.6(3.4)$ & $94.9(0.4)$ & $89.2(2.5)$ & $100.7(2.0)$ \\
\hline 234 & Thiamethoxam & 0.1 & 0.5 & $99.8(1.8)$ & $92.4(1.1)$ & $83.2(1.2)$ & $107.3(1.3)$ \\
\hline 235 & Thiazopyr* & 0.5 & 1 & $100.4(3.2)$ & $93.4(1.8)$ & $88.4(2.6)$ & $105.9(0.8)$ \\
\hline 236 & Thidiazuron & 0.1 & 0.5 & $111.0(2.6)$ & $96.8(1.2)$ & $81.6(8.8)$ & $107.0(2.8)$ \\
\hline 237 & Thifensulfuron-methyl & 0.01 & 0.05 & $106.2(4.2)$ & $99.4(1.8)$ & $113.4(4.0)$ & $113.8(2.3)$ \\
\hline 238 & Thiobencarb & 0.1 & 0.5 & $97.9(1.5)$ & $90.9(1.4)$ & $93.3(5.2)$ & $102.9(1.0)$ \\
\hline 239 & Thiodicarb & 0.05 & 0.2 & $105.5(2.8)$ & $97.5(1.2)$ & $45.2(2.9)$ & $79.6(0.9)$ \\
\hline 240 & Thiophanate-methyl & 18 & 20 & $111.6(6.5)$ & $106.5(0.5)$ & $99.4(0.8)$ & $116.5(0.5)$ \\
\hline 241 & Triadinil & 3 & 5 & $98.4(15.0)$ & $93.3(7.6)$ & $105.6(10.4)$ & $115.7(1.6)$ \\
\hline 242 & Tolclofos-methyl ${ }^{*}$ & 5 & 10 & $88.2(6.6)$ & $90.4(4.8)$ & $97.0(15.1)$ & $101.6(2.4)$ \\
\hline 243 & Tolylfluanid* & 4 & 5 & $259.6(55.8)$ & $66.7(45.2)$ & $314.2(10.9)$ & $184.7(19.2)$ \\
\hline 244 & Triadimefon & 0.5 & 1 & $105.7(2.6)$ & $93.3(1.4)$ & $87.3(4.9)$ & $108.4(2.2)$ \\
\hline 245 & Triazophos & 0.01 & 0.05 & $103.1(1.6)$ & $94.5(0.4)$ & $88.8(1.0)$ & $104.5(1.8)$ \\
\hline 246 & Tricyclazole & 0.01 & 0.05 & $107.4(4.0)$ & $100.4(0.5)$ & $88.7(5.2)$ & $102.4(1.5)$ \\
\hline 247 & Trifloxystrobin & 0.05 & 0.1 & $99.5(1.7)$ & $93.5(1.0)$ & $86.7(2.4)$ & $102.0(0.8)$ \\
\hline 248 & Triflumizole & 0.05 & 0.1 & $112.1(3.0)$ & $104.9(2.1)$ & 103.5(1.9) & $107.0(0.7)$ \\
\hline 249 & Triflumuron & 0.05 & 0.5 & $100.4(4.7)$ & $92.9(1.3)$ & $87.4(3.1)$ & $107.0(0.7)$ \\
\hline 250 & Uniconazole & 0.8 & 1 & $97.4(1.7)$ & $92.3(2.1)$ & $95.3(2.3)$ & $100.0(3.0)$ \\
\hline 251 & Vamidothion & 0.005 & 0.01 & $105.2(1.4)$ & $96.2(0.7)$ & $90.1(1.3)$ & $101.0(1.7)$ \\
\hline
\end{tabular}

*41 pesticides were analyzed by both GC-MS/MS and LC-MS/MS.

한계(limit of quantitation, LOQ)를 측정하기 위해 제조한 표준품 혼합용액을 $0.005 ~ 100 \mu \mathrm{g} / \mathrm{L}$ 로 희석하여 각각 3 반복 으로 분석하였다. 각 농약의 $\mathrm{LOD}$ 는 $\mathrm{LC}-\mathrm{MS} / \mathrm{MS}$ 분석에서 $0.005 \sim 18 \mu \mathrm{g} / \mathrm{kg}$, GC-MS/MS에서 $0.08 \sim 80 \mu \mathrm{g} / \mathrm{kg}$ 수준이었 으며, LOQ는 LC-MS/MS분석에서 $0.01 ~ 20 \mu \mathrm{g} / \mathrm{kg}$, GC-MS/ $\mathrm{MS}$ 의 경우 $0.1 \sim 100 \mu \mathrm{g} / \mathrm{kg}$ 범위로 나타나 시료 중에 함유된 $\mathrm{ppb}$ 수준의 미량 농약성분의 검출이 가능할 것으로 판단되
었다(Table 5, 6).

\section{농약성분별 회수율}

회수율 실험은 친환경인증을 받은 사과와 쌀 시료에 최종 농도가 $50 \mu \mathrm{g} / \mathrm{kg}, 200 \mu \mathrm{g} / \mathrm{kg}$ 되도록 표준품 혼합용액을 시 료에 첨가하여 $\mathrm{QuEChERS}$ 전처리 방법으로 추출한 시험용 액을 $\mathrm{LC}-\mathrm{MS} / \mathrm{MS}$ 와 $\mathrm{GC}-\mathrm{MS} / \mathrm{MS}$ 에 적용하여 회수율을 검증 
Table 6. Average recovery and RSD of 110 pesticides spiked in apple and rice at two different concentrations with GC-MS/MS ( $\mathrm{n}=3$ )

\begin{tabular}{|c|c|c|c|c|c|c|c|}
\hline \multirow[t]{2}{*}{ No. } & \multirow[t]{2}{*}{ Compound } & \multirow{2}{*}{$\begin{array}{c}\text { LOD } \\
(\mu \mathrm{g} / \mathrm{kg})\end{array}$} & \multirow{2}{*}{$\begin{array}{c}\text { LOQ } \\
(\mu \mathrm{g} / \mathrm{kg})\end{array}$} & \multicolumn{2}{|c|}{$\begin{array}{c}\text { Recovery, \% (RSD, \%) } \\
\text { Apple }\end{array}$} & \multicolumn{2}{|c|}{$\begin{array}{c}\text { Recovery, \% (RSD, \%) } \\
\text { Rice }\end{array}$} \\
\hline & & & & $50 \mu \mathrm{g} / \mathrm{kg}$ & $200 \mu \mathrm{g} / \mathrm{kg}$ & $50 \mu \mathrm{g} / \mathrm{kg}$ & $200 \mu \mathrm{g} / \mathrm{kg}$ \\
\hline 1 & Acrinathrin & 20 & 30 & $85.9(4.9)$ & $90.1(5.9)$ & $72.2(1.7)$ & $54.5(2.8)$ \\
\hline 2 & Alachlor ${ }^{*}$ & 1 & 5 & $79.3(7.3)$ & $92.0(5.0)$ & $100.3(6.0)$ & $91.2(12.5)$ \\
\hline 3 & Aldrin & 3 & 5 & $77.9(5.1)$ & $91.3(7.3)$ & $93.8(5.0)$ & $92.6(8.6)$ \\
\hline 4 & Anilofos & 1 & 5 & $83.5(4.4)$ & $95.2(4.7)$ & $78.9(1.6)$ & $35.9(2.8)$ \\
\hline 5 & $\mathrm{BHC}$ & 1 & 5 & $76.9(8.3)$ & $92.3(4.6)$ & $94.4(8.9)$ & $88.9(12.0)$ \\
\hline 6 & Bifenox & 0.08 & 0.1 & $89.4(2.1)$ & $92.5(5.1)$ & $91.2(1.3)$ & $81.3(1.0)$ \\
\hline 7 & Bifenthrin & 1 & 5 & $95.0(5.4)$ & $102.6(5.8)$ & $72.2(1.5)$ & $54.5(0.9)$ \\
\hline 8 & Bromobutide & 1 & 3 & $80.7(7.4)$ & $95.6(5.8)$ & $102.9(4.7)$ & $94.0(11.1)$ \\
\hline 9 & Bromopropylate & 0.08 & 0.1 & $86.0(6.3)$ & $97.6(5.2)$ & $88.3(2.4)$ & $87.2(0.9)$ \\
\hline 10 & Butachlor & 1 & 2 & $85.8(5.6)$ & $99.8(5.2)$ & $101.9(3.1)$ & $92.3(6.7)$ \\
\hline 11 & Captan & 20 & 30 & $37.6(1.7)$ & $27.0(4.8)$ & $65.0(6.6)$ & $37.3(14.2)$ \\
\hline 12 & Carbofuran* & 0.3 & 0.8 & $101.5(14.7)$ & $105.7(6.8)$ & $101.5(13.4)$ & $112.9(5.2)$ \\
\hline 13 & Carbophenothion & 5 & 10 & $86.0(5.6)$ & $98.4(5.6)$ & $88.5(2.1)$ & $79.5(0.5)$ \\
\hline 14 & Chinomethionat & 30 & 50 & $34.6(3.5)$ & $22.7(5.7)$ & $44.5(1.5)$ & $30.1(1.5)$ \\
\hline 15 & Chlordane & 0.3 & 0.5 & $85.0(7.1)$ & $93.2(5.1)$ & $94.2(5.9)$ & $89.8(7.4)$ \\
\hline 16 & Chlorfenapyr & 5 & 10 & $98.1(7.3)$ & $101.1(6.0)$ & $98.0(1.7)$ & $89.2(3.8)$ \\
\hline 17 & Chlorfenvinphos & 1 & 5 & $79.4(7.1)$ & $96.7(5.3)$ & $95.7(3.8)$ & $86.9(5.9)$ \\
\hline 18 & Chlorfluazuron* $^{*}$ & 3 & 5 & $104.8(9.1)$ & $111.1(6.4)$ & $126.1(4.2)$ & $130.5(9.7)$ \\
\hline 19 & Chlorobenzilate & 1 & 5 & $86.3(6.6)$ & $99.9(5.2)$ & $89.8(0.4)$ & $83.6(2.4)$ \\
\hline 20 & Chlorothalonil & 5 & 10 & $80.5(2.7)$ & $86.0(6.4)$ & $90.7(10.2)$ & $87.2(12.8)$ \\
\hline 21 & Chlorpropham & 1 & 5 & $74.0(9.6)$ & $91.9(2.4)$ & $96.7(10.1)$ & $91.1(13.4)$ \\
\hline 22 & Chlorpyrifos-methyl & 1 & 5 & $75.7(8.6)$ & $91.2(5.3)$ & $96.8(6.9)$ & $85.5(11.8)$ \\
\hline 23 & Cyflufenamid* & 8 & 10 & $81.3(7.8)$ & $93.8(1.6)$ & $62.7(1.4)$ & $49.5(1.6)$ \\
\hline 24 & Cyfluthrin & 30 & 50 & $84.1(4.1)$ & $88.3(5.6)$ & $77.3(1.2)$ & $64.3(2.9)$ \\
\hline 25 & Cyhalothrin (lambda) & 3 & 5 & $88.6(5.3)$ & $92.3(6.5)$ & $76.8(0.3)$ & $68.5(1.4)$ \\
\hline 26 & Cypermethrin & 10 & 30 & $84.1(2.5)$ & $88.6(6.0)$ & $82.0(1.0)$ & $66.2(1.8)$ \\
\hline 27 & Cyprodinil & 5 & 8 & $84.5(7.9)$ & $95.9(6.7)$ & $99.1(3.8)$ & $93.7(9.6)$ \\
\hline 28 & DDT & 0.1 & 0.3 & $90.0(6.1)$ & $98.4(5.9)$ & $91.8(1.8)$ & $83.7(4.0)$ \\
\hline 29 & Deltamethrin & 10 & 30 & $76.1(4.4)$ & $83.0(5.1)$ & $70.7(3.6)$ & $44.3(8.1)$ \\
\hline 30 & Dichlofluanid $^{*}$ & 1 & 3 & $24.0(0.1)$ & $37.2(1.0)$ & $55.1(0.2)$ & $19.5(5.8)$ \\
\hline 31 & Diclofop-methyl & 10 & 30 & $93.8(9.5)$ & $100.1(6.2)$ & $88.8(1.1)$ & $87.0(0.8)$ \\
\hline 32 & Dicloran & 8 & 10 & $86.0(1.1)$ & $92.2(6.1)$ & $94.3(5.8)$ & $86.0(13.7)$ \\
\hline 33 & Dicofol & 10 & 30 & $89.5(6.9)$ & $105.2(5.4)$ & $96.5(4.1)$ & $92.6(10.5)$ \\
\hline 34 & Dieldrin & 1 & 3 & $88.6(6.1)$ & $93.8(5.3)$ & $90.1(6.5)$ & $88.8(6.0)$ \\
\hline 35 & Demethoate $^{*}$ & 20 & 30 & $79.8(3.4)$ & $94.1(5.3)$ & $85.2(4.6)$ & $76.8(10.6)$ \\
\hline 36 & Dimethylviphos* & 5 & 8 & $74.0(7.5)$ & $91.1(3.8)$ & $86.0(3.8)$ & $75.7(8.5)$ \\
\hline 37 & Diphenylamine & 3 & 5 & $73.8(8.5)$ & $84.9(2.5)$ & $92.5(10)$ & $92.2(17.9)$ \\
\hline \multirow[t]{2}{*}{38} & Disulfoton & 0.5 & 0.8 & $75.2(6.5)$ & $92.0(3.8)$ & $104.5(5.7)$ & $96.4(13.2)$ \\
\hline & Endosulfan sulfate & 25 & 50 & $84.8(7.2)$ & $97.6(3.4)$ & $81.3(4.4)$ & $76.9(1.8)$ \\
\hline \multirow[t]{2}{*}{39} & Endosulfan- $\alpha$ & 1 & 3 & $82.4(6.9)$ & $94.4(6.3)$ & $89.5(4.8)$ & $89.0(9.8)$ \\
\hline & Endosulfan- $\beta$ & 0.8 & 1 & $90.9(5.0)$ & $97.2(6.6)$ & $92.6(2.9)$ & $86.1(4.4)$ \\
\hline 40 & Endrin & 3 & 5 & $89.0(7.7)$ & $95.5(7.8)$ & $92.0(4.7)$ & $83.3(5.9)$ \\
\hline 41 & $\mathrm{EPN}^{*}$ & 1 & 5 & $89.0(4.0)$ & $93.7(5.3)$ & $86.1(1.6)$ & $76.6(1.4)$ \\
\hline 42 & Ethalfluralin & 1 & 5 & $95.4(7.4)$ & $102.3(1.1)$ & $98.1(6.6)$ & $88.9(13.4)$ \\
\hline
\end{tabular}


Table 6. Continued

\begin{tabular}{|c|c|c|c|c|c|c|c|}
\hline \multirow[t]{2}{*}{ No. } & \multirow[t]{2}{*}{ Compound } & \multirow{2}{*}{$\begin{array}{c}\text { LOD } \\
(\mu \mathrm{g} / \mathrm{kg})\end{array}$} & \multirow{2}{*}{$\begin{array}{c}\text { LOQ } \\
(\mu \mathrm{g} / \mathrm{kg})\end{array}$} & \multicolumn{2}{|c|}{$\begin{array}{c}\text { Recovery, \% (RSD, \%) } \\
\text { Apple }\end{array}$} & \multicolumn{2}{|c|}{$\begin{array}{c}\text { Recovery, \% (RSD, \%) } \\
\text { Rice }\end{array}$} \\
\hline & & & & $50 \mu \mathrm{g} / \mathrm{kg}$ & $200 \mu \mathrm{g} / \mathrm{kg}$ & $50 \mu \mathrm{g} / \mathrm{kg}$ & $200 \mu \mathrm{g} / \mathrm{kg}$ \\
\hline 43 & Ethion & 20 & 30 & $101.1(1.7)$ & $100.3(5.2)$ & $90.9(1.5)$ & $82.4(1.5)$ \\
\hline 44 & Etridiazole & 0.3 & 0.5 & $76.8(10.7)$ & $96.4(4.0)$ & $88.4(9.2)$ & $92.2(19.6)$ \\
\hline 45 & Fenamidone* & 1 & 5 & $85.9(7.6)$ & $99.2(7.1)$ & $91.2(3.2)$ & $84.7(2.2)$ \\
\hline 46 & Fenamiphos ${ }^{*}$ & 5 & 10 & $82.3(5.8)$ & $92.6(6.0)$ & $91.3(1.7)$ & $82.4(1.7)$ \\
\hline 47 & Fenitrothion & 5 & 10 & $78.6(6.8)$ & $87.7(4.6)$ & $96.3(7.0)$ & $88.8(9.7)$ \\
\hline 48 & Fenothiocarb ${ }^{*}$ & 1 & 5 & $83.6(5.7)$ & $97.4(5.6)$ & $101.5(4.3)$ & $91.1(4.6)$ \\
\hline 49 & Fenpropathrin & 5 & 10 & $91.2(5.8)$ & $102.7(5.0)$ & $93.1(2.0)$ & $80.9(1.2)$ \\
\hline 50 & Fenvalerate & 10 & 30 & $87.9(2.1)$ & $92.1(5.0)$ & $80.9(1.3)$ & $64.2(2.5)$ \\
\hline 51 & Ferimzone & 80 & 100 & $97.6(2.8)$ & $71.0(1.5)$ & $105.1(2.7)$ & $102.0(6.8)$ \\
\hline 52 & Fipronil & 1 & 3 & $93.1(6.2)$ & $95.2(6.1)$ & $103.5(2.3)$ & $94.6(3.1)$ \\
\hline 53 & Flucythrinate & 8 & 10 & $85.0(2.2)$ & $89.9(5.3)$ & $80.6(1.5)$ & $67.4(3.6)$ \\
\hline 54 & Fludioxonil $^{*}$ & 1 & 5 & $87.5(6.5)$ & $99.5(5.7)$ & $92.1(2.5)$ & $85.9(1.2)$ \\
\hline 55 & Fluopyram* & 10 & 30 & $75.5(7.5)$ & $90.4(0.5)$ & $62.7(1.6)$ & $49.0(7.3)$ \\
\hline 56 & Folpet & 5 & 10 & $66.8(1.5)$ & $85.9(2.5)$ & $72.7(7.0)$ & $46.0(7.4)$ \\
\hline 57 & Fthalide & 5 & 10 & $86.2(7.1)$ & $96.9(3.9)$ & $97.1(3.0)$ & $95.6(8.6)$ \\
\hline 58 & Halfenprox & 5 & 10 & $88.0(2.1)$ & $93.2(5.3)$ & $86.9(0.5)$ & $81.3(1.5)$ \\
\hline \multirow{2}{*}{59} & Heptachlor & 1 & 5 & $73.6(7.9)$ & $87.9(6.0)$ & $93.4(5.9)$ & $88.2(14.7)$ \\
\hline & Heptachlor-epoxide & 1 & 5 & $79.9(8.9)$ & $91.9(6.9)$ & $96.9(6.2)$ & $91.1(12.2)$ \\
\hline 60 & Imazalil $^{*}$ & 25 & 50 & $92.7(9.0)$ & $101.9(8.5)$ & $91.7(6.8)$ & $86.0(2.3)$ \\
\hline 61 & Indanofan & 10 & 25 & $87.9(5.1)$ & $102.6(6.6)$ & $84.0(1.9)$ & $81.8(3.1)$ \\
\hline 62 & Indoxacarb & 10 & 30 & $74.8(3.4)$ & $84.2(4.5)$ & $71.2(1.6)$ & $58.4(5.3)$ \\
\hline 63 & Iprodione & 10 & 30 & $82.6(5.2)$ & $92.7(2.4)$ & $70.0(3.7)$ & $46.4(6.0)$ \\
\hline 64 & Isofenphos & 1 & 5 & $79.8(5.2)$ & $94.0(3.9)$ & $101.8(2.5)$ & $93.4(5.8)$ \\
\hline 65 & Lufenuron* & 1 & 5 & $38.4(7.1)$ & $26.3(1.5)$ & $31.3(5.3)$ & $10.7(17)$ \\
\hline 66 & Mecarbam & 5 & 10 & $77.2(6.9)$ & $95.5(3.6)$ & $96.0(3.9)$ & $89.2(5.6)$ \\
\hline 67 & Methidathion* $^{*}$ & 5 & 8 & $78.6(5.9)$ & $96.8(4.9)$ & $97.5(2.6)$ & $88.0(6.3)$ \\
\hline 68 & Methoxychlor & 0.3 & 0.5 & $93.9(4.2)$ & $103.1(5.0)$ & $92.0(1.3)$ & $86.4(0.6)$ \\
\hline 69 & Metobromuron* & 50 & 80 & $75.9(9.1)$ & $85.6(5.3)$ & $90.6(4.5)$ & $83.2(9.1)$ \\
\hline 70 & Metolachlor $^{*}$ & 1 & 5 & $86.0(5.8)$ & $95.7(10.4)$ & $103.4(3.8)$ & $93.8(7.5)$ \\
\hline 71 & Metribuzin $^{*}$ & 1 & 5 & $74.2(6.3)$ & $88.2(3.0)$ & $97.7(5.9)$ & $89.9(8.9)$ \\
\hline 72 & Mevinphos* & 5 & 10 & $70.7(11.6)$ & $95.3(3.8)$ & $86.1(14.1)$ & $75.6(9.3)$ \\
\hline 73 & Novaluron $^{*}$ & 1 & 5 & $35.6(17.3)$ & $47.2(1.5)$ & $33.7(7.1)$ & $16.5(9.7)$ \\
\hline 74 & Oxyfluorfen & 5 & 10 & $90.6(6.6)$ & $105.1(3.5)$ & $96.0(1.6)$ & $86.8(2.8)$ \\
\hline 75 & Parathion & 3 & 5 & $79.4(5.7)$ & $90.9(5.3)$ & $100.1(3.7)$ & $95.9(8.7)$ \\
\hline 76 & Parathion-methyl & 5 & 8 & $75.5(6.9)$ & $85.8(3.8)$ & $96.1(4.4)$ & $87.4(12.2)$ \\
\hline 77 & Pendimethalin ${ }^{*}$ & 1 & 5 & $80.8(4.6)$ & $91.8(5.2)$ & $98.9(2.0)$ & $92.8(7.4)$ \\
\hline 78 & Penthiopyrad* & 10 & 30 & $82.8(9.3)$ & $94.3(1.4)$ & $54.6(2.0)$ & $41.3(0.6)$ \\
\hline 79 & Permethrin & 10 & 25 & $89.6(5.3)$ & $96.6(6.1)$ & $84.0(2.8)$ & $81.8(1.3)$ \\
\hline 80 & Phorate $^{*}$ & 5 & 10 & $70.3(7.5)$ & $95.2(6.8)$ & $106.3(4.6)$ & $98.8(13.4)$ \\
\hline 81 & Picoxystrobin ${ }^{*}$ & 1 & 5 & $106.1(3.6)$ & $102.7(4.5)$ & $63.0(1.5)$ & 49.1(1.5) \\
\hline 82 & Pirimiphos-ethyl & 1 & 5 & $101.2(4.0)$ & $104.7(2.5)$ & - & - \\
\hline 83 & Probenazole ${ }^{*}$ & 5 & 10 & $81.8(13.0)$ & $97.3(4.5)$ & $35.1(9.4)$ & $31.5(8.5)$ \\
\hline 84 & Procymidone & 10 & 25 & $90.4(4.9)$ & $96.1(7.0)$ & $102.4(3.7)$ & $93.3(8.3)$ \\
\hline 85 & Prometryn ${ }^{*}$ & 5 & 10 & $80.1(9.3)$ & $96.8(5.4)$ & $98.2(5.4)$ & $92.1(8.9)$ \\
\hline
\end{tabular}


Table 6. Continued

\begin{tabular}{|c|c|c|c|c|c|c|c|}
\hline \multirow[t]{2}{*}{ No. } & \multirow[t]{2}{*}{ Compound } & \multirow{2}{*}{$\begin{array}{c}\text { LOD } \\
(\mu \mathrm{g} / \mathrm{kg})\end{array}$} & \multirow{2}{*}{$\begin{array}{c}\text { LOQ } \\
(\mu \mathrm{g} / \mathrm{kg})\end{array}$} & \multicolumn{2}{|c|}{$\begin{array}{c}\text { Recovery, \% (RSD, \%) } \\
\text { Apple }\end{array}$} & \multicolumn{2}{|c|}{$\begin{array}{c}\text { Recovery, \% (RSD, \%) } \\
\text { Rice }\end{array}$} \\
\hline & & & & $50 \mu \mathrm{g} / \mathrm{kg}$ & $200 \mu \mathrm{g} / \mathrm{kg}$ & $50 \mu \mathrm{g} / \mathrm{kg}$ & $200 \mu \mathrm{g} / \mathrm{kg}$ \\
\hline 86 & Propiconazole $^{*}$ & 5 & 10 & $89.6(8.9)$ & $99.7(5.5)$ & $88.8(3.8)$ & $79.9(2.2)$ \\
\hline 87 & Prothiofos & 5 & 10 & $83.3(5.0)$ & $99.4(5.3)$ & $99.2(1.7)$ & $92.1(4.2)$ \\
\hline 88 & Pyridalyl & 5 & 10 & $85.4(2.7)$ & $92.0(5.9)$ & $87.0(1.9)$ & $77.2(2.1)$ \\
\hline 89 & Pyridaphenthion* & 5 & 10 & $85.7(4.9)$ & $95.8(2.3)$ & $78.4(1.8)$ & $69.8(3.5)$ \\
\hline \multirow[t]{4}{*}{90} & Quinoclamine $^{*}$ & 5 & 10 & $74.1(4.2)$ & $83.9(4.7)$ & $86.7(1.6)$ & $80.2(6.6)$ \\
\hline & Quintozene & 50 & 80 & $94.5(8.4)$ & $101.3(2.0)$ & $91.9(6.0)$ & $87.8(12.9)$ \\
\hline & Propiconazole ${ }^{*}$ & 5 & 10 & $89.6(8.9)$ & $99.7(5.5)$ & $88.8(3.8)$ & $79.9(2.2)$ \\
\hline & Prothiofos & 5 & 10 & $83.3(5.0)$ & $99.4(5.3)$ & $99.2(1.7)$ & $92.1(4.2)$ \\
\hline \multirow[t]{4}{*}{91} & Pyridalyl & 5 & 10 & $85.4(2.7)$ & $92.0(5.9)$ & $87.0(1.9)$ & $77.2(2.1)$ \\
\hline & Pyridaphenthion* & 5 & 10 & $85.7(4.9)$ & $95.8(2.3)$ & $78.4(1.8)$ & $69.8(3.5)$ \\
\hline & Methyl-pentachlorophenyl sulfide & 0.1 & 0.3 & $74.9(7.5)$ & $86.7(9.1)$ & $98.7(3.4)$ & $83.1(12.2)$ \\
\hline & Pentachloroaniline & 1 & 5 & $74.3(7.2)$ & $84.8(6.4)$ & $90.9(6.5)$ & $86.1(13.3)$ \\
\hline 92 & Silafluofen* & 1 & 5 & $89.3(2.9)$ & $96.0(5.4)$ & $87.0(0.6)$ & $80.9(2.0)$ \\
\hline 93 & Simazine & 5 & 10 & $71.2(8.1)$ & $91.3(5.6)$ & $98.2(9.2)$ & $90.6(14.5)$ \\
\hline 94 & Simeconazole ${ }^{*}$ & 1 & 25 & $74.7(7.4)$ & $91.1(3.6)$ & $96.3(7.0)$ & $91.2(7.9)$ \\
\hline 95 & Simetryn ${ }^{*}$ & 5 & 1 & $82.1(7.4)$ & $99.1(4.4)$ & $97.8(6.4)$ & $93.0(12.2)$ \\
\hline 96 & Spiromesifen ${ }^{*}$ & 1 & 5 & $83.0(5.5)$ & $97.2(3.0)$ & $82.5(2.9)$ & $74.6(1.3)$ \\
\hline 97 & Tebupirimfos ${ }^{*}$ & 1 & 5 & $75.0(8.4)$ & $91.7(5.1)$ & $99.4(5.0)$ & $89.7(14.4)$ \\
\hline 98 & Tefluthrin & 0.08 & 0.1 & $84.3(8.3)$ & $95.5(7.4)$ & $104.5(8.5)$ & $94.9(15.8)$ \\
\hline 99 & Terbufos & 1 & 5 & $70.9(8.4)$ & $86.6(4.2)$ & $101.3(7.2)$ & $94.0(15.7)$ \\
\hline 100 & Terbutryn $^{*}$ & 5 & 10 & $78.3(6.4)$ & $94.2(5.1)$ & $96.1(5.7)$ & $91.4(10.4)$ \\
\hline 101 & Tetradifon & 1 & 5 & $97.2(1.5)$ & $101.9(5.7)$ & $89.5(1.1)$ & $85.3(0.8)$ \\
\hline 102 & Thiazopyr $^{*}$ & 5 & 10 & $86.7(7.2)$ & $99.2(5.7)$ & $105.3(6.7)$ & $94.9(10.5)$ \\
\hline 103 & Thifluzamide & 1 & 5 & $87.6(6.6)$ & $102.6(5.6)$ & $98.1(0.6)$ & $89.5(2.0)$ \\
\hline 104 & Tolclofos-methyl ${ }^{*}$ & 1 & 5 & $78.3(7.6)$ & $92.2(5.9)$ & $100.4(6.5)$ & $93.2(13.1)$ \\
\hline 105 & Tolylfluanid* & 5 & 10 & $44.9(6.1)$ & $52.6(5.4)$ & $54.7(1.5)$ & $25.6(9.1)$ \\
\hline 106 & Tralomethrin & 1 & 5 & $76.1(4.0)$ & $83.4(4.9)$ & $70.0(3.0)$ & $44.1(8.1)$ \\
\hline 107 & Triadimenol & 5 & 10 & $83.8(7.3)$ & $95.3(5.8)$ & $99.2(2.7)$ & $91.7(4.1)$ \\
\hline 108 & Trifluralin & 1 & 5 & $95.3(2.4)$ & 101.1(1.2) & $99.5(6.7)$ & $91.9(15.8)$ \\
\hline 109 & Vinclozolin & 1 & 5 & $84.8(7.7)$ & $95.7(6.0)$ & $102.4(8.1)$ & $95.0(12.9)$ \\
\hline 110 & Zoxamide & 1 & 5 & $81.0(6.4)$ & $90.0(3.6)$ & $69.9(3.2)$ & $43.5(4.3)$ \\
\hline
\end{tabular}

*41 pesticides were analyzed by both GC-MS/MS and LC-MS/MS.

하였다. 분석대상 농약에 대한 분석법 확립 결과 표준곡선 의 직선성은 $0.05 \sim 0.2 \mathrm{mg} / \mathrm{L}$ 범위에서 $\mathrm{R}^{2}>0.99$ 이었으며 회 수율에 대한 결과는 Table 5과 6에 나타내었다.

$\mathrm{LC}-\mathrm{MS} / \mathrm{MS}$ 분석 대상 농약성분 251성분의 회수율은 사과 시료의 경우 저농도 $(50 \mu \mathrm{g} / \mathrm{kg})$ 에서는 회수율이 $70 ~ 120 \%$ 이 내이고 표준편차 $20 \%$ 이내인 농약은 242 종이었고, 정성이 가능한 성분은 248 종이었으며 benfuracarb, diafenthiuron, fenhexamid 농약 성분 3 종은 검출 할 수 없었다. 고농도 $(200 \mu \mathrm{g} / \mathrm{kg})$ 에서는 회수율이 $70 ~ 120 \%$ 이내이고 표준편차 $20 \%$ 이내인 농약은 242 종이었고, 정성이 가능한 성분은
249종이었으며, benfuracarb, fenhexamid 농약 성분 2종은 검출 할 수 없었다. 쌀시료의 경우 저농도에서는 회수율이 $70 \sim 120 \%$ 이내이고 표준편차 $20 \%$ 이내인 농약은 238 종이 었고, 정성이 가능한 성분은 249종이었으며 benfuracarb, dichlofluanid 농약 성분 2종은 검출 할 수 없었다. 고농도에 서는 회수율이 $70 ~ 120 \%$ 이내이고 표준편차 $20 \%$ 이내인 농약은 243종이었고, 정성이 가능한 성분은 250 종이었으며 dichlofluanid 농약 성분 1종은 검출 할 수 없었다(Table 5).

$\mathrm{GC}-\mathrm{MS} / \mathrm{MS}$ 분석 대상 농약성분 110 성분의 회수율은 사과 시료의 경우 회수율이 $70 ~ 120 \%$ 이내이고 표준편차 $20 \%$ 


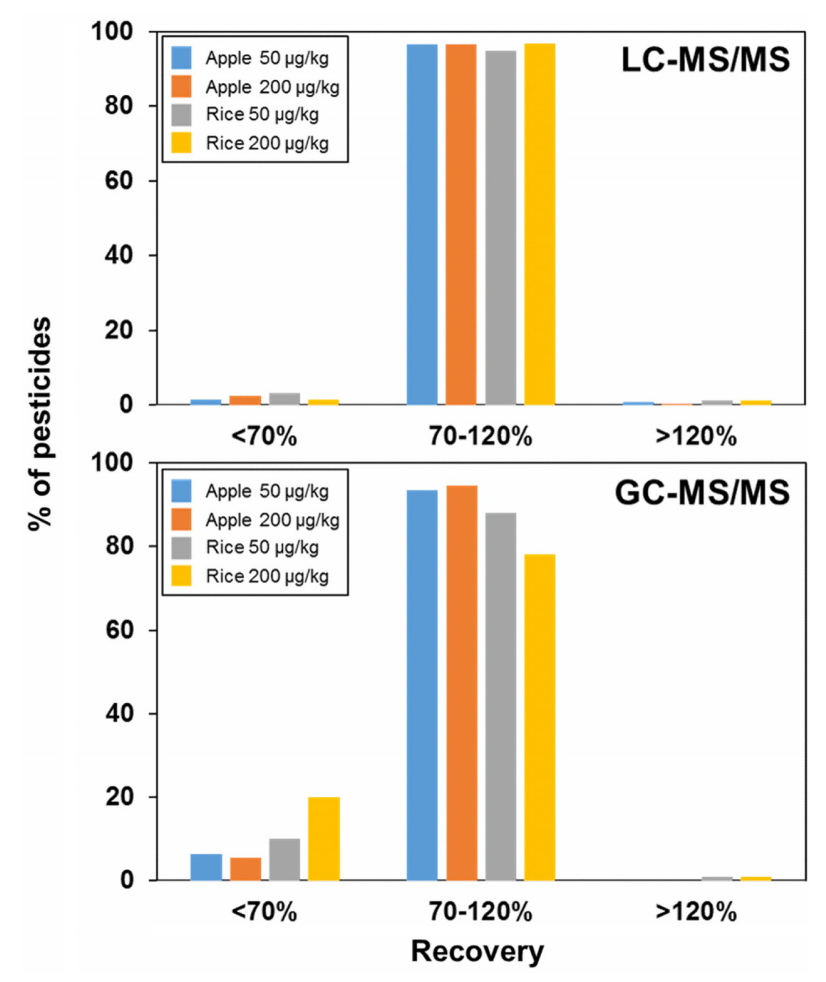

Fig. 2. Distribution of recoveries in apple and rice using two different concentrations with LC-MS/MS and GC-MS/MS.

이내인 농약은 저농도 $(50 \mu \mathrm{g} / \mathrm{kg})$ 와 고농도 $(200 \mu \mathrm{g} / \mathrm{kg})$ 에서 각각 103 종과 104 종이었으며, 모든 농약성분이 검출 되었다. 쌀시료의 경우 저농도와 고농도에서 회수율이 $70 ~ 120 \%$ 이 내이고 표준편차 $20 \%$ 이내인 농약은 97 종이었고, 정성이 가능한 성분은 109 종이었으며 pirimiphos-ethyl 농약 성분 1 종은 검출 할 수 없었다(Table 6).

각국 및 국제기구 등에서 연구수행에 활용된 분석방법에 대한 적합성은 회수율과 상대표준편차 등의 범위를 이용하 여 판단하고 있으며, 국내는 회수율 $70 ~ 120 \%$ 및 상대표준 편차 20\% 이하(Rural Development Administration, 2009), 유럽연합에서 제시한 회수율은 $70 ~ 120 \%$ 와 상대표준편차 $20 \%$ 이하, 국제식품규격위원회는 회수율 $60 \sim 120 \%$ 와 상대 표준편차 15 30\% 이하로 규정하고 있다(Codex Alimentarius Commission, 2003). 본 연구결과에서 LC-MS/MS와 GC$\mathrm{MS} / \mathrm{MS}$ 를 이용한 다종농약 다성분 분석법에서 제시한 회수 율은 최소 $70 \%$ 이상과 상대 표준편차 $20 \%$ 이하로 나타내 어 국내 및 국제적 기준을 충족하였다. 따라서 본 연구에서 적용된 분석방법은 농산물 중 잔류되는 다성분 농약을 분석 하는데 적용될 수 있을 것으로 판단되었다.

LC-MS/MS 분석 대상 농약 중에서 abamectin, chlorfluazuron은 기존에 수행된 선행 연구에서 LC-MS/MS 분석조 건에서 정량이 불가능한 수준의 감도를 보여 분석불가 성분 으로 분류된 바 있고(Kwon 등 2001), Hernando 등(2007)은 abamectine과 같은 macrocyclic lactone 화합물은 HPLC$\mathrm{MS} / \mathrm{MS}$ 의 drying gas 온도를 낮추면 감도를 높일 수 있다고 보고 하였다. Hernando 등(2007)의 연구 결과를 기기분석 조건에 반영 한 결과 사과시료에서 abamectin의 경우 $90 \%$, chlorfluazuron의 경우 $75 \%$ 이상의 회수율을 보임으로써 잔 류농약 다성분 분석 기준인 70 130\% 이내를 만족하는 재 현성이 우수한 결과를 얻을 수 있었다. 사과와 쌀시료에서 공통적으로 검출되지 않은 benfuracarb 농약은 기존의 농약 잔류 연구결과에서 회수율이 잔류농약 다성분 분석 기준보 다 낮은 경향을 보였다(Gwon 등, 2014; Yang 등, 2013). Benfuracarb는 중성 및 염기성 조건에서 음전하를 띄며, 음 전하를 지니는 농약들은 $\mathrm{QuEChERS}$ 정제과정 중 $\mathrm{PSA}$ 에 흡착되는 특성이 있어 회수율이 떨어지고 최종 시료 추출액 이 $\mathrm{pH}$ 6이상의 조건에서는 검출이 되지 않는다는 연구 보 고가 있다(Lehotay, 2003; Sannino 등, 2004). LC-MS/MS와 GC-MS/MS 분석대상 농약 dichlofluanid은 시료 추출과정 또는 시료 추출액의 $\mathrm{pH}$ 의 증가에 의해 빠르게 분해되는 특 징이 있고 질량분석기를 이용한 다성분 동시분석법에서 회 수율이 낮은 성분으로 단성분 분석법으로 정량이 가능하다 고 보고 된바 있다(Cho 등, 2013). 또한, GC-MS/MS 분석 대상 농약인 pirimiphos-ethyl은 사과시료에서는 $100 \%$ 이상 의 회수율을 보였으나 쌀시료에서는 검출되지 않았다. 다른 matrix에 비해 시료 추출단계에서 쌀시료 습윤화 과정을 거 치는 동안 pirimiphos-ethyl 성분이 acetonitrile 층으로 완벽 하게 분리되지 않은 원인이 작용한 것으로 판단되어진다. 따라서 분석효율이 낮거나 미분석 대상 농약에 대해서는 시 료 전처리법의 개선과 분석효율을 증대시키기 위한 추가적 인 연구가 필요할 것으로 사료된다.

\section{결 론}

본 연구에서는 $\mathrm{QuEChERS}$ 시료 전처리법을 적용한 사과 와 쌀 시료로부터 $\mathrm{LC}-\mathrm{MS} / \mathrm{MS}$ 와 $\mathrm{GC}-\mathrm{MS} / \mathrm{MS}$ 를 이용하여 잔류농약 동시다성분 분석의 가능성을 살펴보았다. LC-MS/ $\mathrm{MS}$ 분석대상 농약성분 251종, GC-MS/MS 분석대상 농약 성분 110 종을 적용하여 320 종 농약성분이 본 연구의 다성 분 동시분석법 적용 시험을 통해 정성 및 정량이 동시에 가 능함을 확인하였다. 분석대상 농약성분의 회수율은 70$120 \%$ 의 적정 범위를 나타내었으나(Fig. 2), 이 범위를 벗어 나는 회수율을 나타내는 성분들도 다수 존재하여 이를 개선 하기 위해 분석효율이 낮은 농약성분들에 대해서는 추출방 법 및 추가적인 시험법 적용과 개발이 필요하다고 판단되었 으며, 본 연구에서 검토된 $\mathrm{LC}-\mathrm{MS} / \mathrm{MS}$ 와 $\mathrm{GC}-\mathrm{MS} / \mathrm{MS}$ 를 이용 한 농약의 다성분 동시분석법은 앞으로 농산물의 농약잔류 모니터링 연구 분야에 적용될 수 있을 것으로 기대되었다. 


\section{감사의 글}

본 연구는 안전성평가연구소 기관 고유사업(KK-1510)에 의해 수행되었습니다.

\section{Literature Cited}

Anastassiades, M., S. J. Lehotay, D. tajnbaher and F. J. Schenck (2003) Fast and Easy multiresidue method employing acetonitrile extraction/partitioning and "dispersive solidphase extraction" for the determination of pesticide residues in produce. Journal of AOAC International. 86:412-431.

Bhanti, M. and A. Taneja (2007) Contamination of vegetables of different seasons with organophosphorous pesticides and related health risk assessment in northern India. Chemosphere 69(1):63-68.

Cajka, T., J. Hajslova, O. Lacina, K. Mastovska and S. J. Lehotay (2008) Rapid analysis of multiple pesticide residues in fruit-based baby food using programmed temperature vaporiser injection - low-pressure gas chromatography - high-resolution time-of-flight mass spectrometry. Journal of Chromatography A 1186(1):281-294.

Chamkasem, N., L. W. Ollis, T. Harmon, S. Lee and G. Mercer (2013) Analysis of 136 pesticides in avocado using a modified QuEChERS method with LC-MS/MS and GCMS/MS. Journal of agricultural and food chemistry 61(10):2315-2329.

Cho, T. H., Y. H. Park, H. W. Park, L. H. Hwang, I. S. Cho, M. J. Kim, and Y. Z. Chae (2013) Evaluation of QuEChERS method for determination of pesticide residues using GC/ NPD and GC/ECD. The Korean Journal of Pesticide Science 17(1):65-71.

Codex Alimentarius Commission (2003) Guidelines on good laboratory practice in residue analysis. pp. 25 CAC/GL 401993, Rev.1.

Do, J. A., H. J. Lee, Y. W. Shin, W. J. Choe, K. R. Chae, C. S. Kang and W. S. Kim (2010) Monitoring of pesticide residues in domestic agricultural products. Journal of the Korean Society of Food Science and Nutrition 39(6):902908.

Fenik, J., M. Tankiewicz and M. Biziuk (2011) Properties and determination of pesticides in fruits and vegetables. TracTrends Anal. Chem. 30(6):814-826.

Guana, H., W. E. Brewera, S. T. Garrisb and S. L. Morgana (2010) Disposable pipette extraction for the analysis of pesticides in fruit and vegetables using gas chromatography/ mass spectrometry, Journal of Chromatography A 1217(12): 1867-1874.

Gwon, J. H., T. K. Kim, E. K. Seo, S. M. Hong, H. Y. Kwon, K. S. Kyung, J. E. Kim and N. J. Cho (2014). Multiresidue Analysis of 124 Pesticides in Soils with QuEChERS extraction and LC-MS/MS. Korean Journal of Pesticide
Science 18(4):296-313.

Hernando, M. D., J. M. Suarez-Barcena, M. J. M. Bueno, J. F. Garcia-Reyes and A. R. Fernández-Alba (2007) Fast separation liquid chromatography - tandem mass spectrometry for the confirmation and quantitative analysis of avermectin residues in food. Journal of Chromatography A 1155(1): 62-73.

Ju, O. J., H. Y. Kwon, B. J. Park, C. S. Kim, Y. D. Jin, J. B. Lee and G. J. Im (2011) Analysis of 236 Pesticides in Apple for Validation of Multiresidue Method using QuEChERS Sample Preparation and PTV-GC/TOFMS Analysis. The Korean Journal of Pesticide Science 15(4):401-416.

Koesukwiwat, U., S. J. Lehotay, K. Mastovska, K. J. Dorweiler and N. Leepipatpiboon (2010) Extension of the QuEChERS Method for Pesticide Residues in Cereals to Flaxseeds, Peanuts, and Doughs. Journal of Agricultural and Food Chemistry. 58:5950-5958.

Kwon, H. Y., C. S. Kim, B. J. Park, Y. D. Jin, K. Son, S. M. Hong and G. J. Im (2011) Multiresidue analysis of 240 pesticides in apple and lettuce by QuEChERS sample preparation and HPLC-MS/MS analysis. The Korean Journal of Pesticide Science 15(4):417-433.

Lee, E. Y., H. H. Noh, Y. S. Park, K. W. Kang, S. Y. Jo, S. R. Lee, I. Y. Park, T. H. Kim, Y. D. Jin and K. S. Kyung (2008) Monitoring of pesticide residues in agricultural products collected from markets in Cheongju and Jeonju. Kor. J. Pest. Sci. 12(4):357-362.

Lee, Y. D (2012) Handbook for the pesticide residue analytical methods of Food Code Index. National Institution of Food and Drug Safety Evaluation

Lee, D. Y., Y. J. Kim, M. H. Park, S. H. Lee, S. G. Kim, N. J. Kang and K. Y. Kang (2013) Establishment of Pre-Harvest Residue Limit (PHRL) of Fungicides Azoxystrobin and Difenoconazole on Prunus mume fruits. Kor. J. Pest. Sci. 17(4):307-313.

Lehotay, S. J. (2003) Determination of pesticide residues in foods by acetonitrile extraction and partitioning with magnesium sulfate: collaborative study, Journal of AOAC International 90(2):485-520.

Lehotay, S. J., A. D. Kok, M. Hiemstra and P. V. Bodegraven (2005) Validation of a fast and easy method for the determination of residues from 229 pesticides in fruits and vegetables using gas and liquid chromatography and mass spectrometric detection. Journal of AOAC International 88(2):595-614.

Lehotay, S. J., K. A. Son, H. Y. Kwon, U. Koesukwiwat, W. Fu, K. Mastovska, E. Hoh and N. Leepipatpiboon (2010) Comparison of QuEChERS sample preparation methods for the analysis of pesticide residues in fruits and vegetables. Journal of Chromatography A. 1217:2548-2560.

Pang G. F., C. L. Fan, Y. M. Liu, Y. Z. Cao, J. J. Zhang, B. L. Fu, X. M. Li, Z. Y. Li and Y. P. Wu (2006) Multi-residue method for the determination of 450 pesticide residues in 
honey, fruit juice and wine by double-cartridge solid-phase extraction/gas chromatography-mass spectrometry and liquid chromatography-tandem mass spectrometry Food Additives and Contaminants 23(8):777-810.

Rural Development Administration (2009) Bulletin of Pesticide Registration Investigator (Guidance of pesticide residue test), Notice of Rural Development Administration No. 2009-1. Suwon, Korea.

Sannino, A., L. Bolzoni and M. Bandini (2004) Application of liquid chromatography with electrospray tandem mass spectrometry to the determination of a new generation of pesticides in processed fruits and vegetables. Journal of Chromatography A 1036(2):161-169.

Seo, E. K., T. K. Kim, S. M. Hong, H. Y. Kwon, J. H. Kwon, K. Son and D. H. Kim (2013) Analysis of Systemic Pesticide Imidacloprid and Its Metabolites in Pepper using QuEChERS and LC-MS/MS. The Korean Journal of Pesticide Science. 17(4):264-270.

Yang, I. C., S. M. Hong, H. Y. Kwon, T. K. Kim and D. H. Kim (2013) Multi-residue Pesticide Analysis in Cereal using Modified QuEChERS Samloe Preparation Method. The Korean Journal of Pesticide Science 17(4):314-334.

Zhang, K., J. W. Wong, P. Yang, K. Tech, L. A. DiBenedetto, N. S. Lee, D. G. Hayward, C. M. Makovi, A. J. Krynitsky, K. Banerjee, L. Jao, S. Dasgupta, M. S. Smoker, R. Simonds and A. Schreiber (2011) Multiresidue Pesticide Analysis of Agricultural Commodities Using Acetonitrile Salt-Out Extraction, Dispersive Solid-Phase Sample Clean-Up, and High-Performance Liquid Chromatography-Tandem Mass Spectrometry, Journal of Agricultural and Food Chemistry 59(14):7636-7646.

\title{
LC-MS/MS와 GC-MS/MS를 이용한 사과와 쌀 시료에서 320 종 농약의 다성분 분석
}

\author{
김종환 · 김영진 · 권영상 · 서종수* \\ 안전성평가연구소 환경독성연구센터
}

\begin{abstract}
요 약 본 연구는 사과와 쌀에서 320성분 농약에 대한 다성분 동시분석법을 확립하고자 수행되었다. 시료의 추출 은 QuEChERS법을 사용하였고, 추출 후 잔류물은 LC-MS/MS와 GC-MS/MS로 기기분석 하였다. 시험 농약은 LC$\mathrm{MS} / \mathrm{MS} 251$ 성분, GC-MS/MS 110 성분을 선발하였으며, 41성분은 공통적으로 적용되었다. 분석법의 정량한계는 LC$\mathrm{MS} / \mathrm{MS}$ 에서 $0.01 \sim 20 \mu \mathrm{g} / \mathrm{kg}$, GC-MS/MS에서 $0.1 \sim 100 \mu \mathrm{g} / \mathrm{kg}$ 으로 산출되었다. 사과와 쌀에서 회수율 $70 ~ 120 \%$, 상대 표준편차 $20 \%$ 이내의 조건을 충족한 성분은 LC-MS/MS로 분석한 농약 중 각각 242 성분( $96 \%$ )과 237성분(94\%)로 나타났으며, GC-MS/MS로 분석한 농약 중에는 각각 103성분(94\%)과 83성분(76\%)로 나타났다. 본 연구를 통해 $\mathrm{QuEChERS} \mathrm{전처리와} \mathrm{LC-MS/MS} \mathrm{및} \mathrm{GC-MS/MS를} \mathrm{이용한} \mathrm{분석법은} \mathrm{농산물(사과} \mathrm{및} \mathrm{쌀)} \mathrm{중} \mathrm{잔류농약} \mathrm{다성분} \mathrm{동시}$ 분석에 효과적으로 적용될 것으로 기대된다.
\end{abstract}

색인어 농약, 다성분동시분석, $\mathrm{QuEChERS,} \mathrm{LC-MS/MS,} \mathrm{GC-MS/MS}$ 